\title{
Telomere Shortening in Neural Stem Cells Disrupts Neuronal Differentiation and Neuritogenesis
}

\author{
Sacri R. Ferrón, ${ }^{1 *}$ M. Ángeles Marqués-Torrejón, ${ }^{1 *}$ Helena Mira, ${ }^{1}$ Ignacio Flores, ${ }^{2}$ Kerrie Taylor, ${ }^{1}$ María A. Blasco, ${ }^{2}$ \\ and Isabel Fariñas ${ }^{1}$ \\ ${ }^{1}$ Departamento de Biología Celular and Centro de Investigación Biomédica en Red en Enfermedades Neurodegerativas, Universidad de Valencia, 46100 \\ Burjassot, Spain, and ${ }^{2}$ Telomeres and Telomerase Group, Molecular Oncology Program, Spanish National Cancer Centre, 28029 Madrid, Spain
}

Proliferation in the subependymal zone (SEZ) and neurogenesis in the olfactory bulb decline in the forebrain of telomerase-deficient mice. The present work reveals additional effects of telomere shortening on neuronal differentiation, as adult multipotent progenitors with critically short telomeres yield reduced numbers of neurons that, furthermore, exhibit underdeveloped neuritic arbors. Genetic data indicate that the tumor suppressor protein p53 not only mediates the adverse effects of telomere attrition on proliferation and selfrenewal but it is also involved in preventing normal neuronal differentiation of adult progenitors with dysfunctional telomeres. Interestingly, progenitor cells with short telomeres obtained from fetal brains do not exhibit any replicative defects but also fail to acquire a fully mature neuritic arbor, demonstrating cell cycle-independent effects of telomeres on neuronal differentiation. The negative effect of p53 on neuritogenesis is mechanistically linked to its cooperation with the Notch pathway in the upregulation of small GTPase RhoA kinases, Rock1 and Rock2, suggesting a potential link between DNA damage and the Notch signaling pathway in the control of neuritogenesis. We also show that telomerase expression is downregulated in the SEZ of aging mice leading to telomere length reductions in neurosphere-forming cells and deficient neurogenesis and neuritogenesis. Our results suggest that age-related deficits could be caused partly by dysfunctional telomeres and demonstrate that $\mathrm{p} 53$ is a central modulator of adult neurogenesis, regulating both the production and differentiation of postnatally generated olfactory neurons.

\section{Introduction}

Aging in mammals is associated with reduced stem cell activity in different organs, leading to deficiencies in cell turnover and tissue repair (Flores et al., 2006; Rando, 2006). Stem cell-based neurogenesis is restricted to two areas in the adult mammalian brain, the subgranular zone of the dentate gyrus and the subependymal zone (SEZ) adjacent to the lateral ventricles (Zhao et al., 2008). In the SEZ, a slowly cycling population of glial fibrillary acidic protein (GFAP) + astroglia/radial glia-like cells act as neural stem cells (NSCs), which primarily produce olfactory bulb (OB) interneurons (Zhao et al., 2008). Adult neurogenesis declines with age, but the reasons are still unclear, although they may include

\footnotetext{
Received Aug. 6, 2009; accepted Aug. 14, 2009.

This work was supported by grants from Ministerio de Ciencia e Innovación (Programa de Biomedicina), Ministerio de Sanidad y Consumo (Centro de Investigación Biomédica en Red en Enfermedades Neurodegerativas and Red Tercel), Generalitat Valenciana (Programa Prometeo), and Fundación "la Caixa" (I. Fariñas). M.Á.M.-T. is a predoctoral fellow of the Formación de Personal Investigador-Ministerio de Education y Ciencia program. We are grateful to $D$. van der Kooy and M. Serrano for kindly providing constructs. We thank M. P. Rubio for help with constructs, M.J. Palop for assistance with the mouse colonies, and A. Pérez for providing material from aged animals.

*S.R.F. and M.Á.M.-T. contributed equally to this work.

Correspondence should be addressed to Isabel Fariñas, Departamento de Biología Celular, Universidad de Valencia, 46100 Burjassot, Spain. E-mail: isabel.farinas@uv.es.

S. R. Ferrón's present address: Department of Physiology, Development, and Neuroscience, University of Cambridge, Cambridge CB2 3EG, UK.

H. Mira's present address: Departamento de Biología Celular y del Desarrollo, Instituto de Salud Carlos III, 28220 Majadahonda, Spain.

I. Flores's present address: Stem Cell Group, Spanish National Center for Cardiovascular Research, 28029 Madrid, Spain.

DOI:10.1523/JNEUROSCI.3836-09.2009

Copyright $\odot 2009$ Society for Neuroscience 0270-6474/09/2914394-14\$15.00/0
}

changes in niche signals and/or cell-intrinsic factors (Tropepe et al., 1997; Jin et al., 2003; Enwere et al., 2004; Maslov et al., 2004; Luo et al., 2006; Molofsky et al., 2006; Ahlenius et al., 2009).

Telomere maintenance appears to be essential for the prolonged persistence of stem cell function in organs with extensive cell turnover, and, consistently, adult stem cells exhibit high levels of telomerase, the ribonucleoprotein complex that extends telomere sequences after cell division (Caporaso et al., 2003; Flores et al., 2006, 2008). However, telomerase cannot completely prevent telomere shortening after extensive stem cell division, providing a putative mechanism for the timely limit of stem cell replicative history and subsequent progressive decay in the maintenance of organ homeostasis at old ages (Flores et al., 2006; Herbig et al., 2006). Long-term maintenance of adult neurogenic niches appears to depend on telomere dynamics, as NSCs in the SEZ of late generation telomerase-deficient (Terc) mice become exhausted, leading to significant reductions in OB neurogenesis (Ferrón et al., 2004).

Proper development of a neuronal population not only requires the generation of correct numbers of neuroblasts, but it is also dependent on the execution of appropriate terminal differentiation programs that ensure successful integration of newly generated neurons into functional neural circuits. Olfactory neurons produced in the adult SEZ participate in odor stimuli discrimination (Lledó et al., 2006) and therefore maintenance of a successful neurogenic process contributes to OB normal physiology. Telomerase expression in neural progenitors is downregulated during neuronal differentiation (Kruk et al., 1996; Caporaso 
et al., 2003; Cheng et al., 2007) and telomerase overexpression can inhibit neuronal differentiation in neural cell lines (Richardson et al., 2007), suggesting that telomere lengths/telomerase activity may modulate neuronal differentiation. However, potential effects of telomere dysfunction on neural differentiation remain unknown.

We show that telomeres shorten with age in NSCs of the SEZ and that telomerase-deficient mice exhibit reduced neurogenesis but also impaired neuronal differentiation and neuritogenesis. Additional analyses in NSCs with short telomeres obtained from fetal brains demonstrate that altered neuronal differentiation and neuritogenesis are independent from telomere effects on cell cycling. We also show that effects of telomere dysfunction on neuritogenesis are mediated by $\mathrm{p} 53$-dependent regulation of the expression of RhoA effectors Rock 1 and Rock 2 and that this regulation can be modulated by cooperation with the Notch pathway.

\section{Materials and Methods}

Animals. Terc $^{+1-}$ and $p 53^{+/-}$mice were intercrossed to generate $\mathrm{Terc}^{+-}$; $p 53^{+1-}$ double-heterozygous mice, and these mice were then mated to generate first generation $\left(\mathrm{G}_{1}\right)$ Terc $^{-1-} p 53^{+/-}$littermates. $\mathrm{G}_{1}$ Terc $^{-1-}$; $p 53^{+/-}$littermates were then interbred for successive generations to obtain late-generation $\mathrm{G}_{3}$ Terc $^{-1-} ; p 53^{-1-}$ double-mutant mice as well as their corresponding Terc $^{-1-}$ littermate controls (Chin et al., 1999). $\mathrm{G}_{5}$ Terc $^{-1-}$ embryos were obtained from $\mathrm{G}_{4}$ pregnant mothers derived from successive generations of crosses between $\operatorname{Terc}^{-1-}$ mice. The genetic background for all genotypes was a pure C57BL/6 background. Housing of mice and all experiments were performed according to European Union 86/609/EEC and Spanish RD-1201/2005 guidelines, following protocols approved by the corresponding local ethics committees.

Histological analysis. Mice received seven intraperitoneal injections of $50 \mu \mathrm{g} / \mathrm{g}$ body weight 5-bromo-2' -deoxyuridine (BrdU) (one every $2 \mathrm{~h}$ ) and were killed either $1 \mathrm{~h}$ (for measurement of the proliferation labeling index) or 1 month (for determination of label retaining cells) after the last injection. Adult mice were transcardially perfused with $4 \%$ paraformaldehyde (PFA) in $0.1 \mathrm{M}$ phosphate buffer, $\mathrm{pH} 7.4$ (PB), and their brains were dissected and postfixed by immersion in the same fixative for $2-4 \mathrm{~h}$. The brains of mice receiving BrdU injections on the day of killing were embedded in paraffin and serially sectioned into 7 - $\mu \mathrm{m}$-thick sections, which were processed for the immunofluorescent detection of BrdU, GFAP, calretinin (CR), and $\beta$ III-tubulin. The brains of mice receiving long-term injections of BrdU were serially sectioned into $30 \mu \mathrm{m}$ coronal sections using a vibratome and used for the detection of BrdU, GFAP, Sox2, and CR. The following primary antibodies were used: mouse anti-BrdU (Dako; 1:250) and $\beta$ III-tubulin (clone Tuj1; 1:300; Covance); rabbit anti-GFAP (1:200; Dako), S100 $\beta$ (1:100; Dako), and CR (1:2000; Swant); and goat anti-Sox2 (1:50; R\&D Systems). The immunocytochemical procedures were done according to published protocols (Ferrón et al., 2004, 2007). Control samples without the addition of the primary antibodies yielded no signal. Immunofluorescent samples were analyzed and photographed using a fluorescence-equipped Nikon E600 microscope or a Leica Multispectral confocal microscope, and fluorescent individual images were merged using Adobe Photoshop. Colocalizations in multiple immunofluorescences were always analyzed in confocal series by the use of orthogonal projections. For quantitations, some structures were sampled by selecting predetermined areas on each section and some others were sampled by analyzing entire structures on each section. Every sixth section $(180 \mu \mathrm{m})$ from vibratome series of the $\mathrm{OB}$ was selected and stained for BrdU and CR. Four predetermined areas $(50 \times 50 \mu \mathrm{m})$ in the granule and periglomerular cell layers were analyzed on each section, and all immunopositive cells in these selected areas were counted. GFAP + cells in the SEZ were counted in every 20th section of the paraffin series $(140 \mu \mathrm{m})$ using four predetermined areas $(50 \times 50$ $\mu \mathrm{m})$. Graphs show the relative number of label-retaining cells (LRCs), of LRCs that are CR+ (\%CR/LRC), or of GFAP + cells. Some other labelings were sampled by analyzing the entire SEZ on each section. All BrdU and $\beta$ III-tubulin + cells were counted in every 20th section of the paraffin series, and all GFAP+/Sox $2+/$ LRCs were scored in every sixth vibratome section. The absolute volume of the SEZ was calculated using a point-counting grid following the Cavalieri method in equivalent sections stained with cresyl violet acetate using a CAST-GRID software package (Olympus) adapted to an Olympus BX51 microscope. Cell counts were calculated and presented in the graphs as the total number of cells per SEZ. Volume of the OB was calculated using the same method. The SEZ volume was measured from the rostral tip of the crossing of the corpus callosum and extending caudally to the rostral tip of the crossing of the anterior commissure. The OB volume was measured between the rostral tip of the olfactory ventricle and the rostral limit of the accessory olfactory bulb.

Cell culture. Methods for adult NSC culture and self-renewal assessment have been previously described in detail (Ferrón et al., 2007). Neurosphere growth medium contained $20 \mathrm{ng} / \mathrm{ml}$ epidermal growth factor (EGF) and $10 \mathrm{ng} / \mathrm{ml} \mathrm{FGF2.} \mathrm{Methods} \mathrm{for} \mathrm{embryonic} \mathrm{cultures} \mathrm{and} \mathrm{for}$ growth curve determination have also been previously described (Ferrón et al., 2004). All experiments were performed in neurosphere cultures before passage 10. For differentiation assays, cells were resuspended in control medium supplemented only with FGF2 $(10 \mathrm{ng} / \mathrm{ml})$ at a density of $100,000 \mathrm{cells} / \mathrm{ml}$ and plated onto Matrigel $(15 \mathrm{mg} / \mathrm{ml}$ stock solution diluted 1:100 in control medium; BD Biosciences)-coated glass coverslips. After $2 \mathrm{~d}$ in vitro (div), the medium was removed and control medium supplemented with $2 \%$ FBS (Invitrogen) was added to improve neuronal survival and glial maturation. For clonal differentiation assays, individual neurospheres were attached to Matrigel and allowed to differentiate as described above. Striatal neurons obtained from embryonic day 14.5 (E14.5) embryos were plated on poly-D-lysine and cultured in D-MEM F12 with $10 \%$ FBS for 7 div. Cells, neurospheres, and striatal neurons were fixed in $4 \%$ PFA in PBS $(0.09 \% \mathrm{NaCl}$ in $\mathrm{PB})$ for $15 \mathrm{~min}$ and examined using immunocytochemistry. Inhibitors $\{1 S$-benzyl-4 $R$-[1-(1Scarbamoyl-2-phenylethylcarbamoyl)-1S-3-methylbutylcarbamoyl]-2Rhydroxy-5-phenylpentyl \}carbamic acid tert-butyl ester (L-685.458) (1 $\mu \mathrm{M})$, added 2 div after plating, and (S)-(+)-2-methyl-1-[(4-methyl-5isoquinolinyl)sulfonyl] homopiperazine (H-1152) $(1 \mu \mathrm{M})$, added at the time of plating, were both from Calbiochem. L-685.458 was dissolved in DMSO and control cultures were treated with $0.1 \%$ of the vehicle. For direct cocultures, wild-type (WT) or $\mathrm{G}_{5} \mathrm{Terc}^{-1-}$ fetal neurosphere cells infected with green fluorescent protein (GFP)-carrying retrovirus (see below) were mixed with equal numbers of nontransduced wild-type cells and seeded for differentiation. Neuronal yield and neuritogenesis were analyzed by scoring and measuring all GFP-positive and GFP-negative $\beta$ III-tubulin + cells in the cultures.

Cell transduction and luciferase assays. One million cells harvested in neurosphere medium were seeded in a $75 \mathrm{ml}$ flask and electroporated after 2 div with $3 \mu$ g of pcDNA-gfp or pcDNA-mTert-gfp constructs using an Amaxa nucleofector following the manufacturer's instructions ( $260 \mathrm{~V} ; 1 \mathrm{mFa}$; A33 program). Cells were dissociated $24 \mathrm{~h}$ after nucleofection and seeded in 24-well plates for the differentiation assay. For p53 transactivation experiments, cells were conucleofected with pBR322PIG3-luciferase (Contente et al., 2002) and with $1 \mu \mathrm{g}$ of pRLTK plasmid (Promega) carrying a Renilla luciferase. After a $48 \mathrm{~h}$ incubation at $37^{\circ} \mathrm{C}$, the cells were washed three times with PBS and lysed by adding 100 $\mu \mathrm{l} /$ flask lysis buffer solution for $20 \mathrm{~min}$ at $4^{\circ} \mathrm{C}$. Firefly and Renilla luciferase activities were detected in cell lysates with the Dual Luciferase Assay System (Promega), following the manufacturer's instructions, and measured in a Micro Lumat P96V luminometer. Promoter activity was determined as the ratio between the firefly and Renilla luciferase activities, giving the $1 \mathrm{U}$ value to the activity of the promoter in the differentiated and proliferating wild-type cells. Luciferase activity in nucleofected cells that were subsequently treated with the genotoxic drug adriamycin, which results in a significant increase in p53 activity, was used in each test as a positive control. peGFP-CMV/Luc, pMXIE-gfp, and pMXIE-Notch1IC-gfp retroviruses were prepared as previously described (Hitoshi et al., 2002). Twenty-four hours after infection with the supernatants and $0.1 \mu \mathrm{M}$ polybrene transduced cells were isolated by fluorescence-activated cell sorting using a MoFlow sorter (Dako) and plated in neurosphere or differentiation media. 
Immunocytochemistry. Fixed cells were washed three times with PB and incubated in PB containing 10\% normal goat serum and $0.3 \%$ Triton X-100 (blocking buffer) for $30 \mathrm{~min}$. For triple immunofluorescent detection of neural derivatives, coverslips were incubated with mouse anti$\beta$ III-tubulin (clone Tuj1; 1:300; Covance), rabbit anti-GFAP (1:250; Dako), and rat anti-O4 (1:3; Developmental Studies Hybridoma Bank) primary antibodies for $12 \mathrm{~h}$ at $4^{\circ} \mathrm{C}$. After several washes in PBS, immunoreactivity was detected with $\mathrm{Cy} 3$-conjugated donkey-anti-mouse (1:1500; Jackson ImmunoResearch Laboratories), Alexa Fluor 350conjugated anti-rabbit (1:200; Invitrogen), and biotinylated goat anti-rat (1:300; Vector Laboratories) followed by Cy2-labeled streptavidin (1: 200; Jackson ImmunoResearch Laboratories). The following antibodies were also used: mouse anti-nestin (undiluted; Developmental Studies Hybridoma Bank), rabbit anti-activated caspase 3 (1:100; Cell Signaling Technology), p53 (1:500; Novocastra), Notch intracellular domain (NICD) (1:200; Abcam), S100 $\beta$ (1:100; Dako), or MAP2 (1:500; Santa Cruz Biotechnology), and goat anti-GFP (1:500; Abcam). Immunoreactivities were detected with Alexa Fluor 488-conjugated (1:500; Invitrogen) or Cy3-conjugated (1:1500; Jackson ImmunoResearch Laboratories) secondary antibodies. Cells were counterstained with $4^{\prime}, 6^{\prime}$-diamidino-2phenylindole (DAPI), washed in $\mathrm{PB}$, and mounted with Fluorsave (Calbiochem). Immunofluorescent samples were analyzed and photographed using a Nikon Eclipse E600 microscope equipped with a digital camera and fluorescent images combined using Adobe Photoshop.

Neuritic-dendritic measurements. Differentiated cultures were stained with mouse anti- $\beta$ III-tubulin and appropriate fluorescence-conjugated secondary antibodies as described above. No less than 60 randomly chosen neurons from each of three independent experiments per genotype were photographed at a $400 \times$ magnification in a Nikon E600 microscope equipped with fluorescence and a CCD camera. Neuritic arbors of photographed neurons were traced and the drawings were analyzed by direct counting of the end points as a measurement of neuritic complexity. For measurement of dendrites in vivo, randomly selected $\mathrm{CR}+$ neurons in the granular layer of the $\mathrm{OB}$ that were also positive for the detection of BrdU injected a month before killing were drawn at a $400 \times$ magnification in a Nikon E600 microscope equipped with fluorescence and a CCD camera and the longest dendrite measured using the Scion Image software package.

Confocal quantitative telomere fluorescence in situ hybridization. Dispersed neurospheres extracted from 2- and 12-month-old mice were centrifuged onto microscope slides using a cytospin (Cytospin 3; Thermo Fisher Scientific). After air drying, cells on slides were fixed in methanol/ acetic acid (3:1) for $1 \mathrm{~h}$ and dried overnight. For telomere length quantification on interphasic nuclei, slides were hybridized with a PNA-tel Cy3-labeled probe, and telomere length was determined as described previously (Flores et al., 2008). DAPI and Cy3 signals were acquired simultaneously into separate channels using a confocal ultraspectral microscope (Leica TCS-SP2-A-OBS-UV) using a PL APO $20 \times / 0.70$ PH 2 as lens with Leica LCS software and maximum projections from image stacks ( 10 sections at steps of $1.0 \mu \mathrm{m}$ ) were generated for image quantification. The DAPI image was used to define the nuclear area and the Cy3 image to quantify of telomere fluorescence. The binary DAPI mask was applied to the matching $\mathrm{Cy} 3$ to obtain a combined image with telomere fluorescence information for each nucleus. $\mathrm{Cy} 3$ fluorescence intensity (telomere fluorescence) was measured as "average gray value" (total gray value/nuclei area) units (arbitrary units of fluorescence). These "average telomere fluorescence" values always represent the average Cy3 pixel intensity for the total nuclear area, and not the average value of individual telomere spot intensities, therefore ruling out that differences in nuclear size may influence telomere length measurements.

RNA isolation and semiquantitative and quantitative PCR analyses. RNA was extracted using a RNeasy MicroKit (QIAGEN) and $1 \mu \mathrm{g}$ of RNA was reverse transcribed into cDNA using random 6 bp oligonucleotides ( $3 \mu \mathrm{g} / \mu \mathrm{l}$; Invitrogen) and $200 \mathrm{U}$ of SuperScript II RT reverse transcriptase (Invitrogen), in a reaction volume of $40 \mu \mathrm{l}$ in the presence of first-strand buffer ( $50 \mathrm{~mm}$ Tris- $\mathrm{HCl}, 75 \mathrm{~mm} \mathrm{KCl}, 3 \mathrm{mM} \mathrm{Mg}_{2} \mathrm{Cl}$ ), $5 \mathrm{~mm}$ DTT, and $0.25 \mathrm{~mm}$ each of dNTPs (GE Healthcare) for $2 \mathrm{~h}$ at $42^{\circ} \mathrm{C}$. For PCR analysis, $1 \mu \mathrm{l}$ of cDNA was used as template in a reaction volume of $20 \mu \mathrm{l}$ containing $4 \mathrm{~mm}$ Tris- $\mathrm{HCl}, 20 \mathrm{~mm} \mathrm{KCl}, 20 \mu \mathrm{M}$ EDTA, $200 \mu \mathrm{M}$ DTT,
$0.25 \mathrm{~mm}$ dNTPS (GE Healthcare), $0.25 \mu \mathrm{M}$ primers (Sigma-Genosys), 1 $\mathrm{U}$ of TaqDNA polymerase (Eppendorf), and appropriate primer sequences (supplemental Table 1, available at www.jneurosci.org as supplemental material). The PCRs were conducted under the following cycling conditions: initial denaturation at $94^{\circ} \mathrm{C}$ for $5 \mathrm{~min}$, followed by 40 cycles consisting of denaturation at $94^{\circ} \mathrm{C}$ for $30 \mathrm{~s}$, primer annealing at $60^{\circ} \mathrm{C}$ for $30 \mathrm{~s}$ and extension at $72^{\circ} \mathrm{C}$ for $30 \mathrm{~s}$, followed by an additional final extension at $72^{\circ} \mathrm{C}$ for $10 \mathrm{~min}$. Actin PCR parameters were identical except for the annealing temperature $\left(59^{\circ} \mathrm{C}\right)$ and the number of cycles (20). After densitometry of the ethidium bromide-stained bands, the expression levels were normalized with respect to $\beta$-actin. Real-time quantitative PCR for Tert determination at different ages was performed in a DNA Engine 2 Opticon detection system (Bio-Rad) using SYBR Green I as a double-strand DNA-specific binding dye. Thermocycling was performed in a final volume of $20 \mu \mathrm{l}$ containing $2 \mu \mathrm{l}$ of cDNA sample (diluted 1:5), 20 pmol of each primer (supplemental Table 1, available at www.jneurosci.org as supplemental material), $2 \mathrm{mM} \mathrm{MgCl}_{2}, 0.2 \mathrm{~mm}$ dNTP mixture, $1 \times$ Taq reaction buffer, $0.5 \mathrm{U}$ of HotStart TaqDNA polymerase, and $0.5 \mu \mathrm{l}$ of a 1:3000 dilution of SYBR Green I.

Statistical analyses. Data are always presented as the mean \pm SEM and the number of experiments performed in independent cultures/animals $(n)$ are indicated. Tests of variance homogeneity, normality, and distribution were performed to ensure that the assumptions required for standard parametric ANOVA were satisfied. Statistical analyses were performed by ANOVA to compare group means. In all analyses, the null hypothesis was rejected at $\geq 0.05$. For comparisons between relative values, these were first normalized by using an arcsin transformation.

\section{Results}

\section{Deficient neurogenesis and neuritogenesis during aging correlates with reductions in telomere lengths in adult SEZ NSCs}

OB neurogenesis declines with age as a consequence of the loss of slowly cycling NSCs (Enwere et al., 2004; Maslov et al., 2004). The committed progeny of SEZ NSCs are $\beta$ III-tubulin + neuroblasts and these have also been shown to decrease in number during aging (Luo et al., 2006). Accordingly, when we injected BrdU a month before killing to label newly generated neurons in the $\mathrm{OB}$, we detected reduced densities of BrdU + neurons in the granular and periglomerular layers of the $\mathrm{OB}$ of 12-month-old mice compared with young 2-month-old mice. Neuroblasts generated in the SEZ terminally differentiate in the OB into different types of inhibitory interneurons [i.e., those positive for the calcium binding proteins calretinin $(\mathrm{CR})$ and calbindin $(\mathrm{CB})$ or for tyrosine hydroxylase (TH)] (Whitman and Greer, 2007). When we combined BrdU immunohistochemistry with the detection of the interneuron-specific marker CR, we observed that the density of BrdU-LRCs that were CR + was decreased in old mice (Fig. $\left.1 A, A^{\prime}, B\right)$. But more interestingly, newborn $\mathrm{CR}+$ neurons in the $\mathrm{OB}$ granular layer of aged mice appeared less differentiated and displayed significantly shorter dendrites than in 2-month-old mice (mean length of the longest neurite per CR + BrdU-LRC \pm $\mathrm{SEM}, 13.4 \pm 0.8 \mu \mathrm{m}$ in 2-month-old mice and $9.2 \pm 0.6 \mu \mathrm{m}$ in 12-month-old mice; $n=3$ independent animals per age; $p<$ 0.05 ) (Fig. $\left.1 A, A^{\prime}\right)$. These results are in line with the previous report that dendritic growth of newly born neurons is significantly retarded in the aged dentate gyrus (Rao et al., 2005).

Multipotent self-renewing NSCs can be grown in vitro as clonal aggregates named "neurospheres" in the presence of EGF and FGF2 and differentiated to the three major neural lineages when seeded without EGF onto an adhesive substrate (Reynolds and Weiss, 1992; Ferrón et al., 2007). Neurosphere cultures isolated from the SEZ of 12-month-old mice produced numbers of neurons equivalent to those of young mice (percentage of $\beta$ IIItubulin + cells, $16.7 \pm 0.4$ vs $15.4 \pm 1.1$, respectively; $n=3$ 
A

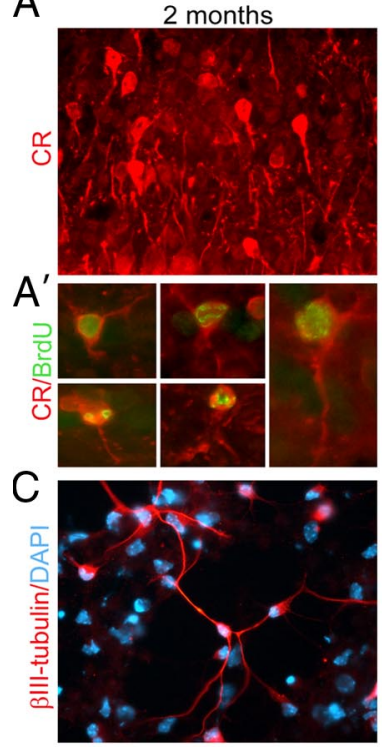

12 months

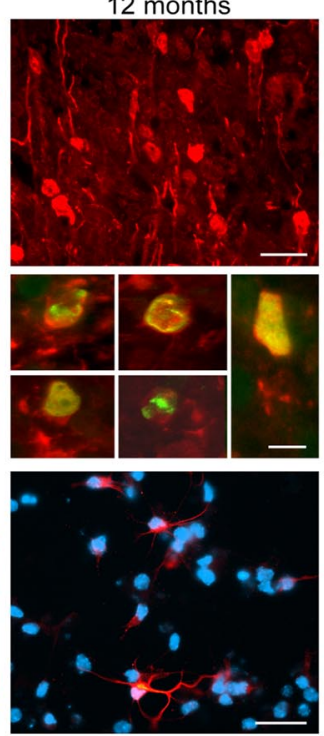

B

\begin{tabular}{rrr} 
& \multicolumn{2}{c}{ OB (granular layer) } \\
\hline age (months) & \multicolumn{1}{c}{2} & \multicolumn{1}{c}{12} \\
\hline LRC & $43.9 \pm 6.6$ & $14.4 \pm 1.8^{*}$ \\
\%LRC/CR & $5.1 \pm 0.6$ & $1.6 \pm 0.2^{* *}$ \\
\hline
\end{tabular}

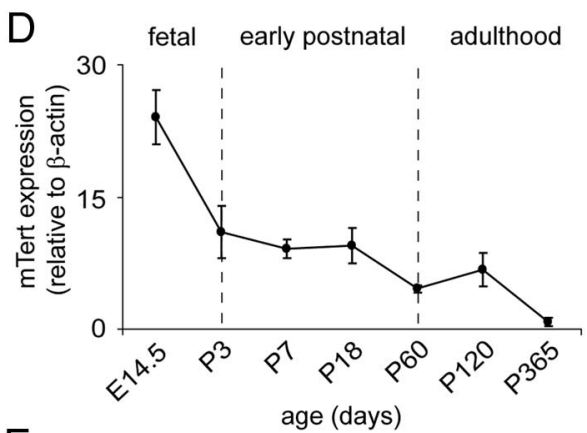

E

\begin{tabular}{crr} 
& \multicolumn{2}{c}{ neurospheres } \\
\hline age (months) & \multicolumn{1}{c}{2} & \multicolumn{1}{c}{12} \\
\hline mTert expression (a.u) & $2.2 \pm 0.4$ & $1.3 \pm 0.3^{* *}$ \\
telomere length (a.u) & $67.9 \pm 3.2$ & $52.5 \pm 3.4^{*}$
\end{tabular}

Figure 1. Telomere shortening and neuritogenesis defects are associated with aging. $A$, Fluorescent micrographs showing the labeling of granular neurons with anti-CR antibodies in the $0 B$ of 2- and 12-month-old mice. $A^{\prime}$, High-power micrographs showing newly born CR + neurons (red), which have incorporated and retained BrdU (green) injected 1 month before the killing of the animal. Notice that $C R+$ neurons appear less differentiated in old animals. $B$, Table showing the relative number of $B r d U-L R C s$ and the percentage of $C R+B$ rdU- $L R C s$ in the granular layer of the $0 B$ in 2-and 12-month-old mice ( $n=3$ mice per age). $C, \beta$ III-tubulin + neurons differentiating in neurosphere cultures obtained from 12-month-old mice exhibit shorter and less developed neuritic arbors when compared with cultures from 2-month-old mice. $D$, Measurement of the levels of the mRNA of the enzyme telomerase (Tert) relative to $\beta$-actin levels, in tissue homogenates from E14.5 ganglionic eminences and from the SEZ of early postnatal (P), adult, and aged mice ( $n=3$ mice per age). $\boldsymbol{E}$, Table showing the quantification of the levels of the mRNA of Tert relative to $\beta$-actin levels and the relative length of telomeres in neurosphere cells isolated from 2 - and 12 -month-old mice ( $n=3$ independent cultures per age; a.u., arbitrary units). Error bars indicate $S E M .{ }^{*} p<0.05$, ${ }^{* *} p<0.01$. Scale bars: $\boldsymbol{A}, 30 \mu \mathrm{m} ; \boldsymbol{A}^{\prime}, 10 \mu \mathrm{m} ; \boldsymbol{C}, 30 \mu \mathrm{m}$.

independent cultures per age) when they were seeded in Matrigel and differentiated for 7 div, in agreement with previous reports (Ahlenius et al., 2009). However, and in agreement with our in vivo results, $\beta$ III-tubulin + neurons in 12 -month-old cultures had fewer neuritic end points (as a measurement of the degree of neurite branching and complexity) compared with those in 2 -month-old cultures (mean number of end points per $\beta$ IIItubulin + neuron \pm SEM, $12.4 \pm 0.8$ and $9.0 \pm 0.7$, respectively; $n=3$ independent animals per age; $p<0.01$ ) (Fig. 1C). Thus, our data demonstrated deficits in neuritogenesis in addition to previously reported deficits in neurogenesis in aging mice.

Telomerase is expressed by cells in neurogenic regions of the adult mouse brain (Caporaso et al., 2003); however, telomapping analysis indicates that telomeres do shorten with age in adult stem cell populations including those of the dentate gyrus (Flores et al., 2008), suggesting potential temporal changes in telomerase activity. Measurements of mRNA levels for the enzyme component of the telomerase complex (Tert) in tissue homogenates from the ganglionic eminences of E14.5 embryos and from the SEZ of early postnatal, adult, and aged mice indicated a progressive reduction in telomerase levels (Fig. $1 D$ ). Tert levels were also reduced in growing neurospheres from 12-month-old relative to 2-month-old mice; consistently, neurosphere cells from 12-monthold mice exhibited telomeres that were significantly shorter than those from young mice in confocal quantitative telomere fluorescence in situ hybridization analysis (Fig. $1 E$ ). These results together suggested potential changes in telomere integrity during normal aging and revealed a correlation between telomerase activity/telomere lengths and age-dependent reductions in stem cell activity, neurogenesis, and neuritogenesis in the SEZ.

We next set out to analyze whether short telomeres do negatively impact on neuritogenesis. Cells from laboratory mouse strains have very long telomeres compared with humans and to wild mice (40-60 vs 5-10 kbp) (Prowse and Greider, 1995; Blasco et al., 1997). Therefore, effects of telomere shortening are usually analyzed in the offspring of several consecutive inbred generations $(\mathrm{G})$ of mice that lack telomerase activity because of targeted deletion of the RNA component of the telomerase complex Terc (Terc mutant mice). At $\mathrm{G}_{4}$ (in a pure $\mathrm{C} 57 \mathrm{BL} / 6$ genetic background) to $\mathrm{G}_{6}$ (in mixed C57BL/6/129Sv background), Tercnull mice exhibit a high incidence of critically short telomeres, reduced fertility, and premature aging phenotypes including shorter life span (Blasco et al., 1997; Herrera et al., 1999; Rudolph et al., 1999; Flores et al., 2005; Flores and Blasco, 2009). We had previously reported that neurosphere cells from the SEZ of young $\mathrm{G}_{2}-\mathrm{G}_{4}$ Terc $^{-1-}$ mice (in a mixed genetic background) exhibited a significant incidence of critically short telomeres and severe defects in the propagation and persistence of GFAP + SEZ cells as well as reduced numbers of $\beta$ III-tubulin + neuroblasts (Ferrón et al., 2004). Similarly, we found reductions in the total numbers of $\mathrm{BrdU}+$ proliferating cells and of $\beta$ III-tubulin + neuroblasts in the SEZ of $\mathrm{G}_{3} \mathrm{Terc}^{-1-}$ mice in a pure C57BL/6 background (supplemental Fig. $1 A-C$, available at www.jneurosci.org as supplemental material). Consistently, we observed a significant reduction in the overall volume of the $\mathrm{OB}$ of $\mathrm{G}_{3}$ Terc-mutant mice (supplemental Fig. $1 D$, available at www.jneurosci.org as supplemental material) along with reduced densities of granular $\mathrm{CR}+$ and $\mathrm{CB}+$ neurons, of periglomerular $\mathrm{TH}+$ neurons, and of BrdU-LRCs and CR + BrdU-LRCs in the granular and periglomerular layers (Fig. 2A,B; supplemental Table 2, available at www. jneurosci.org as supplemental material). These results indicate that neurogenesis to the $\mathrm{OB}$ is significantly reduced in mice bearing critically short telomeres.

Although SEZ neurogenesis was greatly diminished in $\mathrm{G}_{3}$ Terc-mutant mice, the proliferative activity of neuroblasts, measured as the percentage of $\beta$ III-tubulin + cells that incorporated 
A

\begin{tabular}{rcllc} 
& \multicolumn{2}{c}{ LRC } & \multicolumn{2}{c}{$\%$ CR/LRC } \\
\hline layer & granular & periglomerular & granular & periglomerular \\
WT & $53.3 \pm 5.9$ & $3.4 \pm 0.4$ & $5.7 \pm 0.6$ & $3.4 \pm 0.7$ \\
G3 Terc $^{-/-}$ & $10.2 \pm 0.6^{* *}$ & $1.3 \pm 0.2^{*}$ & $0.9 \pm 0.1^{* *}$ & $1.2 \pm 0.2^{*}$ \\
G3 Terc $^{-/-}$;p53 & $56.1 \pm 2.9$ & $3.6 \pm 0.4$ & $4.9 \pm 0.1$ & $3.9 \pm 0.1$ \\
p53 & $118.8 \pm 8.1^{* *}$ & $5.6 \pm 0.1^{* *}$ & $6.3 \pm 0.3$ & $4.8 \pm 0.5$ \\
\hline
\end{tabular}

B
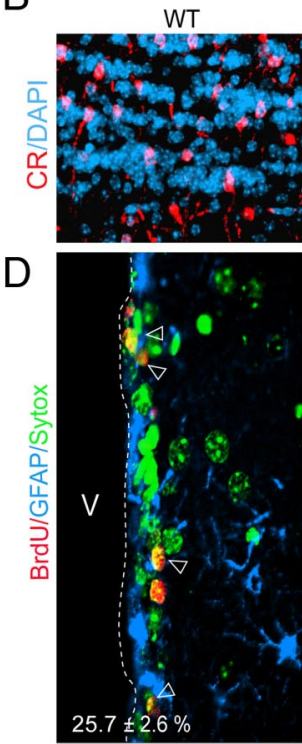

$\mathrm{F}$

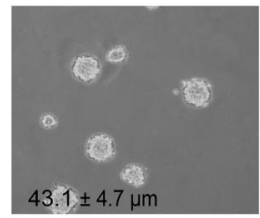

G3 Terc $^{-/-}$
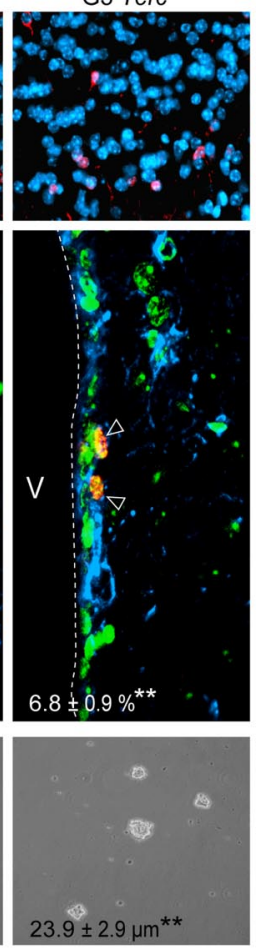

G3 Terc $^{-/-} ; p 53^{-/-}$
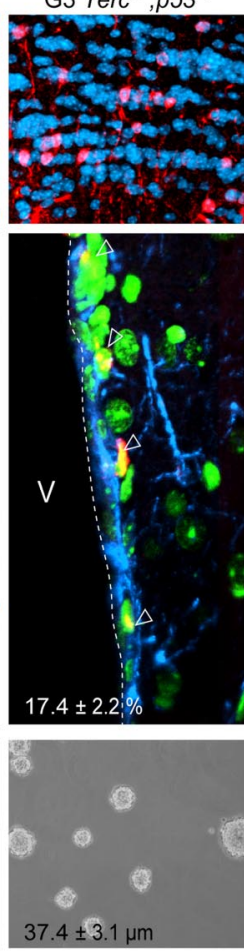
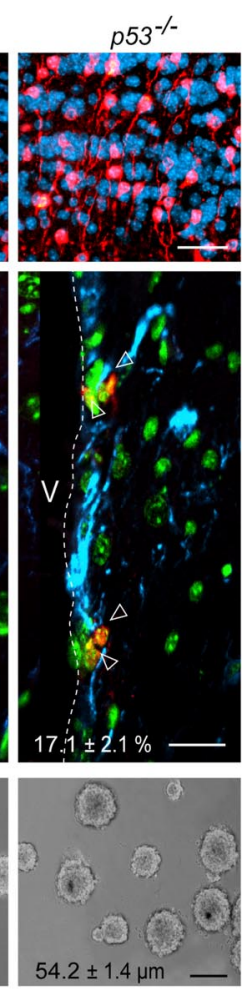

C

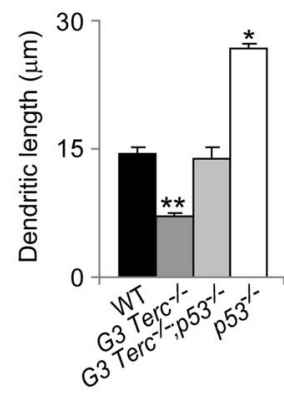

E
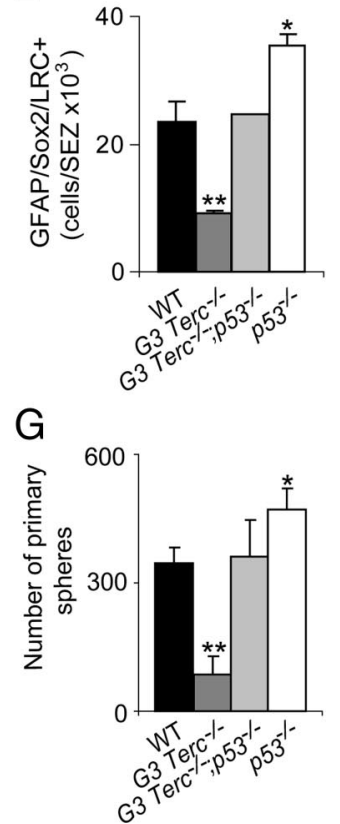

Figure 2. Removal of $\mathrm{p} 53$ is sufficient to rescue defects in proliferation, self-renewal, and differentiation in the SEZ of telomerase-deficient mice. $A$, Table showing the number of BrdU-LRCs and the percentage of $\mathrm{CR}+\mathrm{LRCS}$ in the granular and periglomerular layers of the $\mathrm{OB}$ ofWT, $\mathrm{G}_{3} \operatorname{Terc}^{-1-}, \mathrm{G}_{3} \operatorname{Terc}^{-1-} ; \mathrm{p53}^{-1-}$, and $p 53^{-/-}$2-month-old mice. $B$, Immunofluorescent detection of $\mathrm{CR}+$ interneurons (red) in the granular layer of the $\mathrm{OB}$ of $\mathrm{WT}, \mathrm{G}_{3} \operatorname{Terc}^{-I-}, \mathrm{G}_{3} \operatorname{Terc}^{-1-}, \mathrm{p5} 3^{-1-}$, and $p 53^{-1-}$ 2-month-old mice. Notice that the reduction in the density of $\mathrm{CR}+$ neurons in single Terc mutants is rescued by the 533 loss. DAPI (blue) is used as a nuclear staining. $C$, Graph showing the average length of the longest dendrite per $C R+$ neurons in the granular layer of the $0 B$ in mice of different genotypes ( $n=3$ mice per genotype). D, Fluorescent micrographs from WT, $\mathrm{G}_{3} \operatorname{Terc}^{-1-}, \mathrm{G}_{3} \mathrm{Terc}^{-1-}, \mathrm{p53^{-1- }}$, and $p 53^{-1-}$ SEZs immunostained with anti-GFAP (blue) and anti-BrdU (red) antibodies and counterstained with Sytox (green). The limit with the lateral ventricle $(\mathrm{V})$ is indicated by the white broken line. In white, the percentage of GFAP+ cells that have incorporated BrdU on the day of killing (7 injections; 1 every $2 \mathrm{~h}$ ) \pm SEM. $E$, Graph showing the total number of GFAP +/Sox2 +/LRCs in the SEZ of WT, $\mathrm{G}_{3} \operatorname{Terc}^{-1-}, \mathrm{G}_{3} \operatorname{Terc}^{-1-}$; $p 53^{-1-}$, and $p 53^{-/-}$ 2-month-old mice ( $n=3$ mice per genotype). $\boldsymbol{F}$, Phase contrast micrographs of primary neurospheres obtained from SEZ tissue of mice with different genotypes. The mean diameters (in micrometers \pm SEM) are indicated in each photograph. G, Primary sphere formation in double $p 53$ and telomerase-deficient animals $\left(\mathrm{G}_{3}\right.$ Terc $\left.^{-1-} ; p 53^{-1-}\right)$ is normal relative to control animals (WT) ( $n=3$ independent cultures per genotype). ${ }^{*} p<0.05,{ }^{* *} p<0.01$. Scale bars: $C, 100 \mu \mathrm{m} ; \boldsymbol{D}, 20 \mu \mathrm{m}$.

BrdU injected during the $12 \mathrm{~h}$ period preceding killing (seven injections; one every $2 \mathrm{~h}$ ), did not differ between genotypes (WT, $14.6 \pm 1.1 \% ; \mathrm{G}_{3} \mathrm{Terc}^{-1-}$ mice, $11.9 \pm 2.1 \% ; n=3$ independent animals per genotype). This was a remarkable observation, since the NSCs which gave rise to $\beta$ III-tubulin + neuroblasts in $\mathrm{Terc}^{-1-}$ animals exhibited eroded telomeres and reduced proliferation (Ferrón et al., 2004), and it suggested that proliferation of committed neural progenitors may be insensitive to telomere shortening. Conversely, we observed that normally proliferating $\beta$ III-tubulin + committed neuroblasts in $\mathrm{G}_{3} \mathrm{Terc}^{-1-}$ mice appeared to differentiate poorly. Quantification of the length of the longest dendrite in $\mathrm{CR}+\mathrm{BrdU}-\mathrm{LRCs}$ indicated that $\mathrm{CR}+$ neurons in the $\mathrm{OB}$ granular layer of $\mathrm{G}_{3} \mathrm{Terc}^{-1-}$ mice exhibited shorter dendrites than wild-type neurons (Fig. $2 B, C$ ). Thus, neuroblasts with eroded telomeres exhibit normal proliferation but reduced neuritogenesis.
All deleterious effects of critically short telomeres on adult neurogenesis, including those on neuronal differentiation, are mediated by $\mathrm{p} 53$

Experimental evidence has indicated that telomere dysfunction is sensed by the cell as DNA damage, and hence many senescent phenotypes in telomerase-deficient mice are mediated by effects of activated p53 on the transcription of genes involved in cell cycle arrest and/or apoptosis (Chin et al., 1999; d'Adda di Fagagna et al., 2003; Flores and Blasco, 2009). NSC proliferation defects in the SEZ of young $\mathrm{G}_{2}-\mathrm{G}_{4} \mathrm{Terc}^{-1-}$ mice were associated with increased levels of nuclear p53 (Ferrón et al., 2004), but the potential functional involvement of this tumor suppressor protein in mediating the effects of short telomeres in NSCs was not addressed. To do so, we generated increasing generations of mice that were deficient in both p53 and Terc on a C57BL/6 pure background and analyzed adult 
neurogenesis in $\mathrm{G}_{3} \operatorname{Terc}^{-/-} ; \mathrm{p} 53^{-/-}$as well as in single mutant and wild-type mice.

Measurements of BrdU incorporation in mice of the different genotypes injected seven times with BrdU on the day of killing showed the rescue of the $\mathrm{G}_{3} \operatorname{Terc}^{-1-}$ proliferative defect to wildtype levels in double-mutant animals (supplemental Fig. $1 A$, available at www.jneurosci.org as supplemental material). $G_{3}$ Terc $^{-1-}$ mice showed a specific reduction in the density of GFAP + cells that were present in the SEZ and a decrease in their rate of proliferation, whereas in $\mathrm{G}_{3} \operatorname{Terc}^{-1-} ; \mathrm{p} 53^{-1-}$ and $\mathrm{p} 53^{-1-}$ mice, we found normal GFAP + cell densities and a substantial recovery in the proliferative activity of GFAP + cells (Fig. 2D; supplemental Fig. $1 E$, available at www.jneurosci.org as supplemental material). Consistently, we observed reductions in the total number of GFAP+/Sox $2+$ cells that retained BrdU for a month in the SEZ of $\mathrm{G}_{3}$ Terc $^{-/-}$mice, which were not observed when the telomerase mutation was on a p53-null background (Fig. 2E). The recovery in the number and proliferation of telomerase-deficient NSCs in a p53-null background indicated that p53 was inducing telomere-driven growth arrest in these cells.

In agreement with a decrease in the number of GFAP + / Sox $2+/$ BrdU-LRCs, primary neurosphere yield from $\mathrm{G}_{3}$ Terc $^{-1-}$ mice was reduced when dissociated cells were seeded at very low density, but similar numbers of neurospheres were obtained from $\mathrm{G}_{3} \operatorname{Terc}^{-I-} ; \mathrm{p} 53^{-1-}$ or $p 53^{-/-}$animals relative to wild-type mice (Fig. $2 F, G$ ). Primary neurospheres formed by $\mathrm{G}_{3} \mathrm{Terc}^{-1-}$ cells exhibited a significantly smaller size than those formed from wild-type cells, but this phenotype was also rescued in the absence of p53 (Fig. $2 F$ ).

Self-renewal can be evaluated by assaying the number of cells in the neurosphere culture that are capable of forming new secondary clones. When equal numbers of dissociated cells of different genotypes were replated at low density, we found that the number of secondary spheres was reduced in $\mathrm{G}_{3} \mathrm{Terc}^{-1-}$ cultures. Interestingly, reductions in self-renewal were not noticeable when cells were cultured at higher density (Ferrón et al., 2004), suggesting that autocrine secreted factors may indeed counteract the clonogenic deficiency of cells with short telomeres. The deficit in self-renewal observed in $\mathrm{G}_{3} \operatorname{Terc}^{-1-}$ cultures returned to wild-type values in NSC cultures derived from doubly deficient mice (supplemental Fig. $2 \mathrm{~A}$, available at www. jneurosci.org as supplemental material). As previously reported (Gil-Perotín et al., 2006; Meletis et al., 2006), p53 single mutant neurosphere cells exhibited increased clonogenic capacity, suggesting that $\mathrm{p} 53$ is a negative regulator for self-renewal and, therefore, may act as a limiting factor for stem cell long-term persistence. $G_{3}$ Terc $^{-1-}$ cultures failed to expand for more than three passages (for $\mathrm{G}_{2}-\mathrm{G}_{4}$ Terc $^{-/-}$cultures on a mixed genetic background, see also Ferrón et al., 2004); however, as a result of the recovery in both self-renewal and proliferation kinetics in $G_{3}$ $\operatorname{Terc}^{-1-} ; p 53^{-1-}$ cultures, we obtained normal growth curves at early and late passages allowing for the net expansion of doubly mutant cultures for $>7$ months (supplemental Fig. $2 B$, available at www.jneurosci.org as supplemental material). Consistent with the decrease in self-renewing capacity and in size, $\mathrm{G}_{3}$ Terc $^{-1-}$ neurosphere cells were less multipotent as observed in differentiation clonal analyses in which single neurospheres of either genotype were allowed to differentiate for 7 div and stained with antibodies to $\beta$ III-tubulin (neurons), GFAP (astrocytes), and O4 (oligodendrocytes) (supplemental Fig. 2C, available at www. jneurosci.org as supplemental material). Thus, the reduction in primary and secondary neurosphere numbers and in multipo- tency observed in cultures isolated from $\mathrm{G}_{3} \operatorname{Terc}^{-1-}$ mice was completely rescued by p53 abrogation, indicating that the increase in 53 activity caused by telomere shortening mediates the observed defects in stemness. Interestingly, short telomeres blocked the increased clonogenic capacity of p53-deficient cells, suggesting that telomere shortening can in turn act as a brake in highly proliferative stem cells.

Because of the complete recovery of telomere-driven defects in $\mathrm{G}_{3}$ Terc $^{-1-}$ neurosphere-forming cells lacking p53, we next assayed whether the absence of p53 in double-mutant cells could also fully restore the deficit in neurogenesis observed in lategeneration Terc-mutant mice. Indeed, we observed normal numbers of $\beta$ III-tubulin + cells and normal OB volume (supplemental Fig. $1 B-D$, available at www.jneurosci.org as supplemental material) as well as normal densities of OB LRCs, $\mathrm{CR}+, \mathrm{CB}+, \mathrm{TH}+$, and CR+-LRCs (Fig. $2 A, B$; supplemental Table 2, available at www.

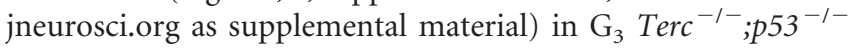
mice. More interestingly, abnormal terminal differentiation of $\mathrm{G}_{3}$ Terc $^{-1-} \mathrm{CR}+$ neurons in the $\mathrm{OB}$ was rescued in double $\mathrm{G}_{3}$ Terc $^{-1-} ; p 53^{-1-}$ mutant animals (Fig. 2 B, C), supporting the notion that p53 activation on telomere damage also interferes with neuronal differentiation in vivo. These rescue experiments suggested that p53 deletion improves the potential of NSCs with dysfunctional telomeres for brain regeneration both at the level of neuronal production and at the level of neuronal differentiation.

\section{p53 mediates negative effects of short telomeres on neuritogenesis}

To further investigate the possibility that normal differentiation of adult NSCs was altered by telomere attrition through p53 activation, cells isolated from the SEZ of $\mathrm{G}_{3} \operatorname{Terc}^{-1-} ; \mathrm{p53}^{-1-}$ mice as well as of single-mutant and wild-type mice were induced to differentiate for 7 div onto Matrigel in the absence of mitogenic stimulation, and the proportions of neurons and glial cells were determined after immunostaining with antibodies to $\beta$ III-tubulin (neurons), GFAP and S100 $\beta$ (astrocytes), and O4 (oligodendrocytes). Quantitative analysis indicated that glial differentiation was normal but that $\beta$ III-tubulin + cells were fewer and their neuritic arbors were less developed in mutant cultures (Fig. 3A-D). No difference in the number of apoptotic neurons was seen by analysis of chromatin condensation in $\beta$ III-tubulin + cell nuclei at 4 (WT, $2.1 \pm 0.2 \% ; \mathrm{G}_{3}$ Terc $^{-1-}, 2.9 \pm 1.2 \% ; n=3$ ) or $7 \mathrm{div}\left(\mathrm{WT}, 2.9 \pm 0.4 \% ; \mathrm{G}_{3}\right.$ Terc $^{-1-}, 2.9 \pm 0.8 \% ; n=3$ ), indicating that the reduction in the number of neurons generated from telomerase-deficient cells was not attributable to decreased neuronal survival. However, more mutant cells remained as nestin + undifferentiated precursors $2 \mathrm{~d}$ after the onset of differentiation (WT, $52.1 \pm 1.9 \% ; \mathrm{G}_{3}$ Terc $^{-1-}, 70.9 \pm 1.1 \% ; n=3$ ), suggesting that telomere shortening negatively impacts on the neurogenic potential of adult neurosphere cells. We next quantitated the morphology of the neuritic arbors by determining the number of end points displayed by $\beta$ III-tubulin + cells; in our 7 div cultures the staining for $\beta$ III-tubulin and the more mature neuronal differentiaton marker MAP2 coincided in the vast majority of neurons (supplemental Fig. 3A, available at www. jneurosci.org as supplemental material). Similarly to the in vivo situation, fully differentiated mutant neurons also exhibited significantly reduced numbers of end points compared with wildtype neurons, indicating that the ability of a neuron to extend neurites may depend on chromosomal integrity (Fig. 3C,D).

Consistent with a role for p53 in mediating the deficit in neuronal yield and neuritogenesis exhibited by telomerase-deficient cells, neurosphere cultures derived from $\mathrm{G}_{3} \operatorname{Terc}^{-1-} ;{\mathrm{p} 53^{-1-}}^{-1}$ 
A

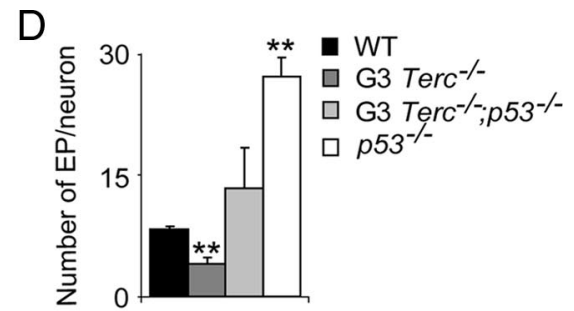

B

\begin{tabular}{|c|c|c|c|c|}
\hline ercentage of $c$ & GFAP & $S 100 \beta$ & $\beta$ III-tubulin & O4 \\
\hline W & $72.1=$ & 0.4 & $11.6 \pm 0.9$ & 1 \\
\hline $\mathrm{m}-$ & & & $0.6^{* *}$ & \\
\hline & & 3 & 10. & $6.6 \pm 0.3$ \\
\hline$p 53^{-/}$ & $3.6 \pm 1.8$ & $12.1 \pm 0.1$ & $15.2 \pm 1.8$ & $5.9 \pm 0.7$ \\
\hline
\end{tabular}

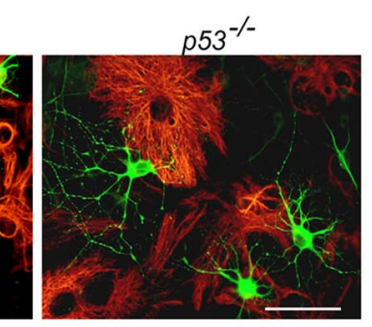

C
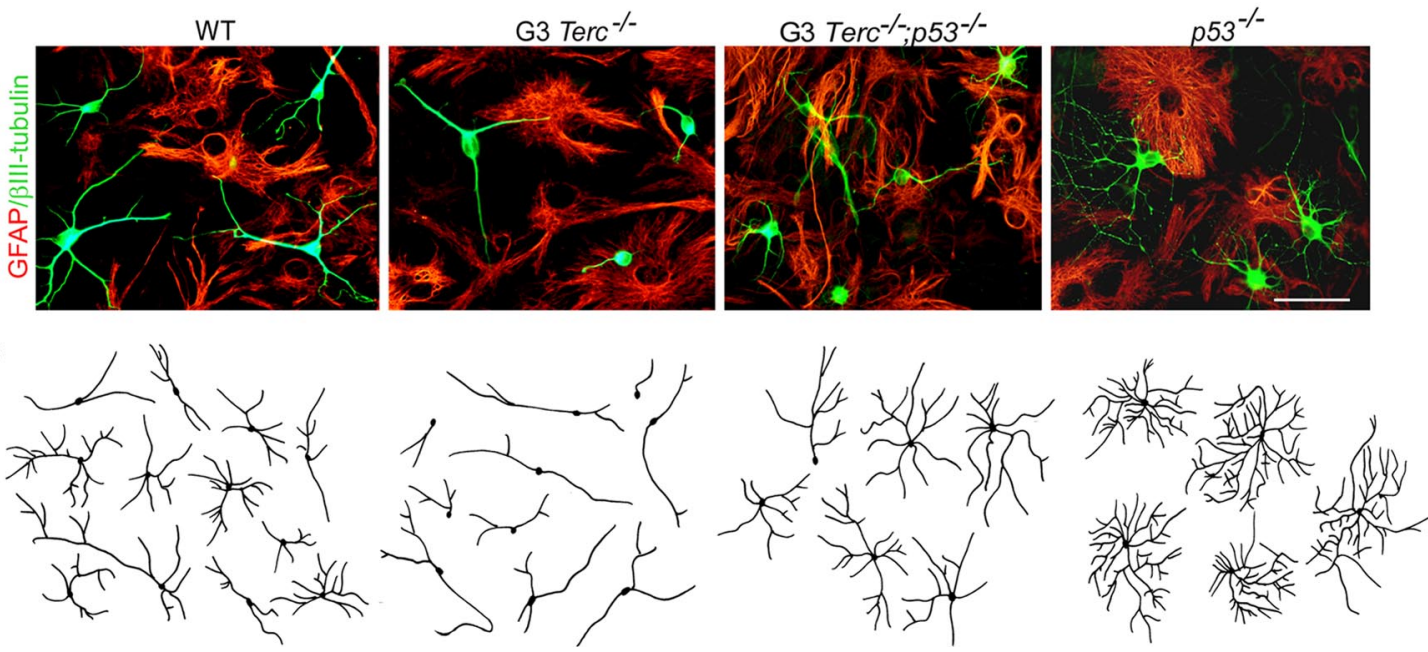

Figure 3. Neurogenic and neuritogenic phenotype restoration in $\mathrm{G}_{3} \operatorname{Terc}^{-I-}$; $p 53$ cells. $A$, Table showing the percentages of GFAP + and $S 100 \beta+$ astrocytes, $\beta$ III-tubulin + neurons, and $04+$ oligodendrocytes in differentiating cultures derived from WT, $\mathrm{G}_{3} \operatorname{Terc}^{-1-}, \mathrm{G}_{3} \operatorname{Terc}^{-1-} ; \mathrm{p5} 3^{-1-}$, and $p 53^{-1-}$ adult young mice. $\mathrm{G}_{3}$ Terc $^{-1-}$ cultures show a reduction in neurogenic potential that is rescued by the $\mathrm{p} 53$ deficiency ( $n=3$ cultures per genotype). $\boldsymbol{B}$, Fluorescent micrographs of WT, $\mathrm{G}_{3} \operatorname{Terc}^{-I-}, \mathrm{G}_{3} \operatorname{Terc}^{-I-}, p 53^{-I-}$, and $p 53^{-I-}$ cultures $^{-1}$ after $7 \mathrm{~d}$ of differentiation showing neurons ( $\beta$ III-tubulin + ; green) and astrocytes (GFAP + ; red). $C$, Representative drawings of $\beta I I I-$ tubulin + neurons differentiated from neurosphere cultures of different genotypes. Notice that mutant neurons are more stunted and less branched than wild types and that this defect is rescued by a p53 deficiency. $\boldsymbol{D}$, Graphs showing quantifications of end points (EP) in $\beta$ III-tubulin + neurons differentiated from WT, $\mathrm{G}_{3}$ Terc $^{-/-}, \mathrm{G}_{3}$ Terc $^{-1-} ; p 53^{-1-}$, and $p 53^{-/-}$cells for 7 div ( $n=3$ cultures per genotype). Error bars indicate SEM. ${ }^{* *} p<0.01$. Scale bar: $\boldsymbol{B}, 30 \mu \mathrm{m}$.

adult mutant mice that had been differentiating for 7 div exhibited wild-type proportions of neurons (Fig. 3A,B). Accompanying this rescue, we observed that the percentage of nestin + undifferentiated progenitor cells at 2 div returned to wild-type levels $\left(\mathrm{G}_{3} \mathrm{Terc}^{-1-}\right.$ / p53 $\left.3^{-l-}, 56.6 \pm 2.2 \% ; n=3\right)$. Likewise, deficient neuritic parameters observed in $\mathrm{G}_{3} \operatorname{Terc}^{-1-}$ cells were also normalized in $\mathrm{G}_{3} \operatorname{Terc}^{-1-}$; $p 53^{-1-}$ cells (Fig. $3 B-D$ ). Together, these results suggested that telomere dysfunction results in defective neurogenesis both at the level of neuronal fate determination/differentiation and at the level of neuritogenesis/maturation, and that both defects are mediated through p53.

Normally proliferating embryonic NSCs with critically short telomeres exhibit specific defects in neuronal differentiation Although the roles of telomerase and of telomere lengths in the proliferation and self-renewal of adult stem cell populations are beginning to be elucidated (Flores et al., 2006), studies on the potential effects of telomere dynamics on stem cell differentiation are very scarce. Deficits in osteogenic potential in mesenchymal stem cells or mobilization defects in hair follicle stem cells in late generation telomerase-deficient mice have been observed (Liu et al., 2004; Flores et al., 2005), but because cells with dysfunctional telomeres usually exhibit abnormal cell cycling, the defect could be a consequence of the deficient proliferative activity of these cells. In a previous report, we had shown that embryonic NSCs (eNSCs) obtained from $\mathrm{G}_{5}$ Terc $^{-1-}$ mutant E14.5 embryos exhibited critically short telomeres but expanded normally in vitro (Ferrón et al., 2004). This provided a very adequate system in which to test whether telomere erosion had effects on cell differentiation that could potentially be independent from effects on cell cycle and/or survival.

To study the impact of telomere damage on the multipotency and differentiation of these eNSCs, we differentiated either single intact neurospheres (clonal differentiation) or cells dissociated from neurospheres (populational differentiation) of either genotype for 7 div and stained them with antibodies to the three major cell lineages (Fig. 4A). We found no significant changes in the frequency of tri/bi/unipotent clones between wild-type and $\mathrm{G}_{5}$ Terc $^{-1-}$ cultures in clonal differentiation analyses (Fig. $4 B$ ), suggesting that telomere damage and/or lack of telomerase do not reduce stemness in eNSCs. In populational differentiation assays, however, we observed that $\mathrm{Terc}^{-1-}$ cells differentiated to wildtype proportions of GFAP + astrocytes and $\mathrm{O} 4+$ oligodendrocytes but to lower proportions of $\beta$ III-tubulin neurons (Fig. $4 C$; supplemental Fig. 3A-C, available at www.jneurosci.org as supplemental material). We could obtain the same results with the neuronal marker MAP2 (Fig. 4D; supplemental Fig. 3A-C, available at www.jneurosci.org as supplemental material). In these assays, the proportion of cells that did not stained for any of the neural markers was increased (Fig. 4C); indeed, the mutation appeared to block neuronal differentiation by retaining a fraction of the committed progenitor cells in an immature state, since we observed an increase in the proportion of cells that stained positive for the undifferentiation marker nestin in mutant relative to control cultures after $2 \operatorname{div}$ (Fig. $4 E$ ). These results suggested that 
A

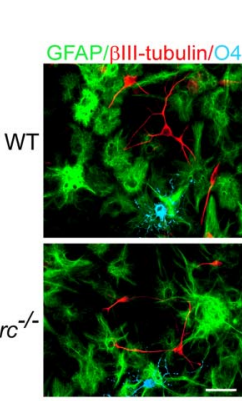

B

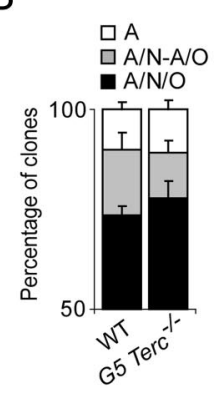

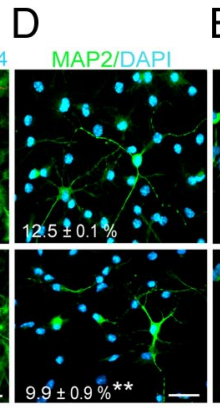

C

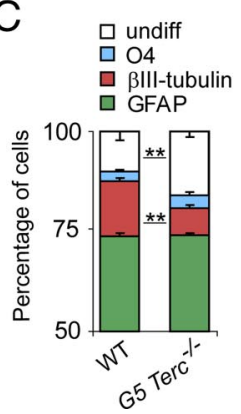

F

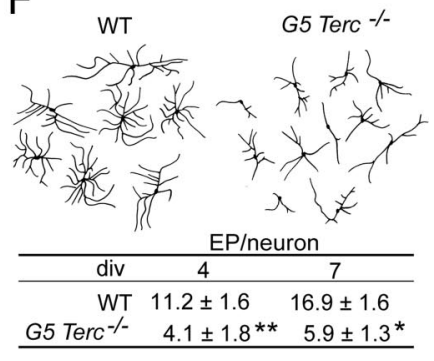

G
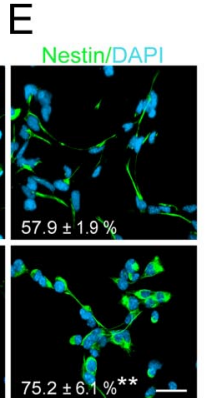

G5 Terc $^{--1}$

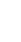

WT

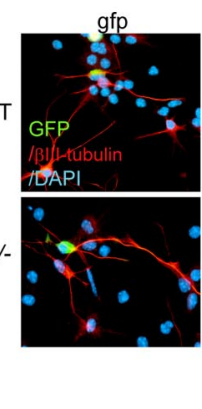

Figure 4. Reduced neurogenesis/neuritogenesis in eNSCs with short telomeres. $\boldsymbol{A}$, Fluorescent micrographs of fetal cultures from WT and from $\mathrm{G}_{5}$ Terc $^{-1-}$ E14.5 embryos immunolabeled for the detection of neurons ( $\beta$ Ill-tubulin + ; red), astrocytes (GFAP+; green), and oligodendrocytes (04; blue). DAPI is used as a nuclear staining. $\boldsymbol{B}$, Proportions of wild-type and $\mathrm{G}_{5}$ Terc $^{-1-}$ neurospheres that produce three (tripotent), two (bipotent), or one (astrocyte-only) cell derivatives. There are no significant differences in the proportion of multipotent clones between wild-type and mutant cultures. $C$, Proportions of $\beta$ III-tubulin + , GFAP +, $04+$ cells, and of undifferentiated (undiff.; negative for any of the three mentioned markers) cells in cultures differentiating from wild-type and from $\mathrm{G}_{5}$ Terc $^{-1-}$ cells ( $n=3$ cultures per genotype). Notice a significant reduction in the proportion of neurons in mutant cultures. D, Fluorescent micrographs of fetal cultures from WT and from $\mathrm{G}_{5}$ Terc $^{-1-}$ E14.5 embryos immunolabeled for the detection of MAP2 (red). DAPI is used as a nuclear staining. The percentage of positive cells relative to total numbers is indicated in white for each genotype. $\boldsymbol{E}$, Micrographs showing the immunofluorescent detection of the marker for undifferentiated cells nestin in cultures differentiated for only 2 div. DAPI is used as a nuclear staining. The percentage of positive cells relative to total numbers is indicated in white for each genotype. $\boldsymbol{F}$, Representative drawings of $\beta$ III-tubulin + neurons differentiated from WT and $\mathrm{G}_{5}$ Terc $^{-1-}$ cells and table showing the numbers of neuritic end points (EP) in WT and $\mathrm{G}_{5}$ Terc $^{-1-}$ $\beta$ III-tubulin + neurons after differentiating for 4 and $7 \mathrm{div}$ ( $n=3$ cultures per genotype). Notice that mutant neurons are more stunted and have fewer branches than wild types. G, Fluorescent micrographs showing $\beta$ Ill-tubulin + neurons (red) differentiated for 2 div from WT and $G_{5}$ Terc $^{-1-}$ neurosphere cells that had been electroporated with gfp-mTert or with gfp alone (GFP+; green). Error bars indicate SEM. ${ }^{*} p<0.05,{ }^{* *} p<0.01$. Scale bars: $\boldsymbol{A}, \boldsymbol{D}, \boldsymbol{E}, \mathbf{G}, 20 \mu \mathrm{m}$.

neural precursors with short telomeres fail to successfully engage the neuronal differentiation program.

We then focused specifically on the neuronal progeny of wildtype and mutant eNSCs. $\mathrm{G}_{5}$ Terc $^{-1-}$ neurons allowed to differentiate for up to 7 div clearly displayed reduced neuritic arbors when compared with wild-type cells (Fig. $4 F$ ). A quantitative analysis of the degree of branching complexity in neurons of the two genotypes that had been differentiating for 7 div revealed significantly reduced numbers of neurites and ramifications in mutant cultures as reflected in the number of end points per neuron (Fig. 4F). These results indicated that telomerasedeficient fetal NSCs that exhibit intact self-renewal and multipotency not only fail to differentiate into normal proportions of neurons, but cells that do acquire this fate poorly mature.

To investigate whether this telomere-dependent neuritogenic phenotype was cell-autonomous, we coseeded wild-type eNSCs together with an equal number of either wild-type or $\mathrm{G}_{5} \mathrm{Terc}^{-1-}$ eNSCs that had been previously infected with a retrovirus carrying gfp and FACS sorted to obtain pure green fluorescent populations that could be easily distinguished in the coculture. We analyzed the proportion and the neuritic branching parameters of both GFP + non-GFP $+\beta$ III-tubulin neurons in all cocultures (supplemental Fig. $4 A$, available at www.jneurosci.org as supple-

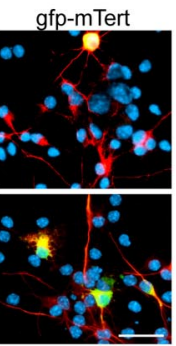

mental material). Mutant GFP + cells differentiated to reduced proportions of $\beta I I I-t u b u l i n+$ neurons that exhibited the characteristic stunted phenotype, and wild-type (non-GFP) neurons differentiated normally whether they were cultured in the presence of mutant GFP+ cells or in the presence of wild-type GFP + cells (supplemental Fig. $4 B$, available at www. jneurosci.org as supplemental material). These data supported a cell-autonomous role of telomere damage on neuronal differentiation.

The enzyme component of the telomerase complex, Tert, can have effects other than telomere reelongation (i.e., directly promoting cell survival) (Shi et al., 2002; Simonsen et al., 2002) (for review, see Blasco, 2002). To investigate whether Tert itself could directly regulate neuronal differentiation, we nucleofected wild-type and $G_{5}$ $\mathrm{Terc}^{-1-}$ proliferating eNSCs with a mouse Tert expression construct (pcDNA-mTertgfp) and seeded transduced cells for differentiation (Fig. 4G). Quantitative analysis of end points in GFP + neurons revealed that transient overexpression of telomerase [1.6 \pm 0.3 -fold change above basal endogenous level in Tert mRNA, as determined by reverse transcription (RT)-PCR] neither modifies neuritogenesis in wild-type cultures (relative number of end points per $\mathrm{GFP}+/ \beta \mathrm{III}-$ tubulin + neuron in gfpmTert vs gfp transduced cultures, $0.9 \pm$ $0.1 ; n=3$ ) nor reverts the neuronal phenotype caused by accumulated telomere erosion in $\mathrm{G}_{5}$ Terc $^{-1-}$ cultures (1.1 \pm $0.2 ; n=3)$. Therefore, we could not detect direct effects of telomerase levels on neuritogenesis.

\section{Abnormal neuronal differentiation of normally proliferating embryonic NSCs correlate with levels of p53}

Our results suggested that telomere attrition results in deficits in neuritogenesis that are independent from cell cycling. We had previously reported that proliferating $\mathrm{G}_{5} \mathrm{Terc}^{-1-}$ eNSCs displayed increased levels of nuclear p53 (Ferrón et al., 2004). In the present work, we could also observe a 10-fold increase in the proportions of cells displaying high levels of nuclear p53 in $\mathrm{G}_{5}$ Terc $^{-1-}$ versus wild-type cultures during differentiation (WT, $5.1 \pm 1.5 \% ; \mathrm{G}_{5} \operatorname{Terc}^{-1-}, 52.5 \pm 4.8 \% ; n=3$ per genotype; $p<$ 0.001). Moreover, luciferase activity assays using the p53responsive PIG3-luciferase reporter demonstrated that p53 was active on both differentiating and proliferating $\mathrm{G}_{5}$ Terc $^{-1-}$ cultures nucleofected with this construct $24 \mathrm{~h}$ before the luminescence assay (Fig. 5A), and consistently, transcript levels for the cell cycle regulator p21, a p53-downstream target, were upregulated in mutant cultures (Fig. $5 B$ ).

Provided the impact of p53 on cell cycle arrest and apoptosis in several cell types (Vogelstein et al., 2000), we sought to determine whether the decrement in neurogenesis observed in mutant cultures could be attributable to a reduction in the proliferation of cells committed to a neuronal fate and/or to promotion of 
neuronal death subsequent to increased levels of p53. A 5 min pulse of BrdU in cultures at 2 div revealed no differences in the percentages of $\beta$ III-tubulin + neuroblasts that were in S-phase between wildtype and mutant cultures (WT, $31.7 \pm$ 9.9\%; $\mathrm{G}_{5}$ Terc $^{-1-}, 36.7 \pm 9.8 \% ; n=3$ independent cultures per genotype). Cell death was also unaffected, as measured by immunostaining for activated caspase 3 during the time course of differentiation (Fig. 5C). These results were consistent with the observed lack of differences in the expression levels of p53-downstream targets involved in the regulation of apoptosis, such as Bax, Noxa, Perp, or PUMA (p53-upregulated modulator of apoptosis), between mutant and wild-type eNSCs (Fig. 5B) and excluded cell death as the mechanism underlying the observed neurogenic defect.

When neurons were specifically examined for p53 immunoreactivity, we observed that $\sim 25 \%$ of all $\mathrm{G}_{5}$ Terc $^{-1-} \beta$ IIItubulin + cells expressed p53 as opposed to only $4 \%$ in wild-type cultures (Fig. 5D). Moreover, defects in the complexity of neuritic arborization appeared to be more prominent in p53-positive $\mathrm{G}_{5}$ Terc $^{-1-}$ mutant neurons when compared with p53-negative ones (Fig. 5D,E). Thus, the accumulation of nuclear p53 was coincidental both with the reduction in the number of neurons and with the poor maturation of eNSCs with short telomeres. All the data together suggested that telomere damage disrupts neuronal differentiation of otherwise normal NSCs through p53 activation.

Because our data suggested specific effects of p53 on neuritogenesis, we cultured postmitotic neurons isolated from the striatum of p53-deficient and wildtype E14.5 embryos. When neuritic arbors were analyzed $7 \mathrm{~d}$ after plating, we found that p53-deficient postmitotic striatal neurons grew larger and more exuberant dendritic arbors than wild-type neurons, as reflected in higher numbers of end points per neuron (WT, $9.3 \pm 1.1 ; p 53^{-/-}$, $17.4 \pm 1.9 ; n=3$ per genotype; $p<0.01$ ) (Fig. $5 F)$. Our results in neurosphere cultures and in acutely dissociated postmitotic neurons indicated that $\mathrm{p} 53$ regulates neuritogenesis during neuronal differentiation in a manner that is independent from its effects on cell cycling.

\section{p53 regulates neuritogenesis through $\mathrm{ROCK} 1 / 2$ in cooperation with the Notch pathway}

Although p53 has been shown to mediate all adverse effects of telomere attrition on cell cycle arrest and/or apoptosis in proliferative cells, including stem cell populations, specific effects of short telomeres and p53 activation on neuronal differentiation have not been extensively investigated. However, some experimental evidence suggest that p53 can play a role in neuronal
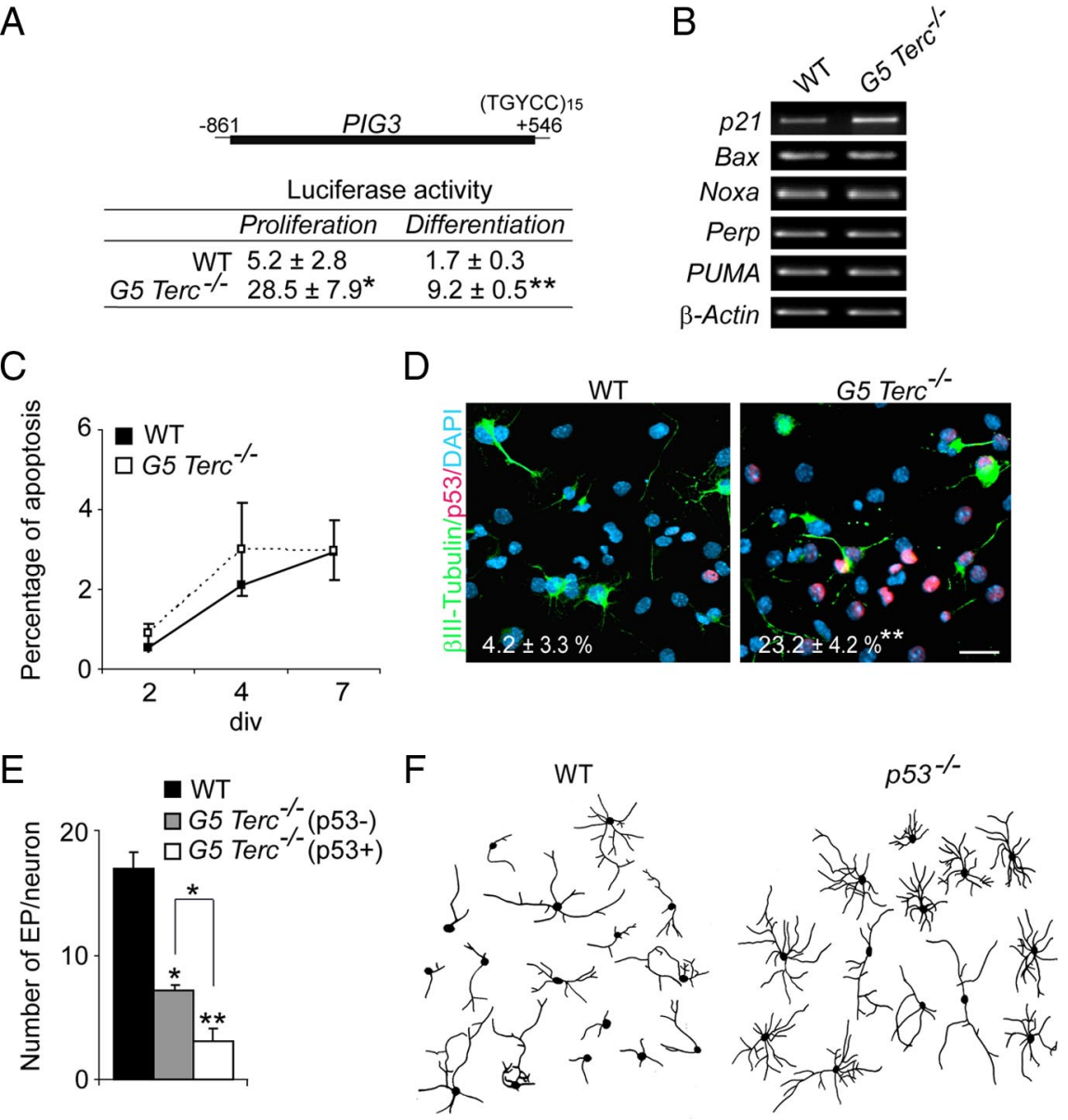

Figure 5. Reduced neuritogenesis in Terc $^{-1-}$ embryonic neurons correlates with $\mathrm{p} 53$ levels. $\boldsymbol{A}$, Luciferase activity (in arbitrary eporter ( $n=3$ cultures/transfections per genotype). B, RT-PCR detection of transcript levels for several p53-downstream genes (cells a $2,4,0 r 7$ div during differentiation ( $n=3$ cultures per genotype). Apoptotic cells are rare in these cultures, and

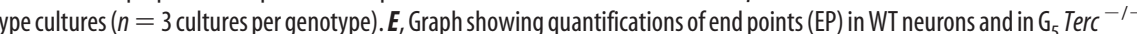
eurons that were either $\mathrm{p} 53$ - or $\mathrm{p} 53$ + at the time of analysis, after 7 div of differentiation ( $n=3$ cultures per genotype). Notice isolated from the striata of WT and $p 53^{-1-}$ E14.5 embryos and cultured for 7 div. Notice the increased number of EP/neuron in $p 53^{-1-}$ striatal neurons. Error bars indicate SEM. ${ }^{*} p<0.05,{ }^{* *} p<0.01$. Scale bar: $\boldsymbol{D}, 20 \mu \mathrm{m}$.

differentiation. A previous genome-wide chromatin immunoprecipitation cloning analysis in PC12 cells indicated that p53 is transcriptionally activated and contributes to NGF-mediated differentiation in this cell line (Brynczka et al., 2007). Moreover, suppression of p53 activity in fetal cerebellar neurons accelerates their terminal differentiation (Ferreira and Kosik, 1996) and in neurospheres from fetal olfactory bulb favors neuronal differentiation (Armesilla-Diaz et al., 2009). Therefore, we decided to investigate the potential mechanism(s) mediating p53 effects on neuronal differentiation and neuritogenesis in populations of adult and fetal neurosphere cells, by focusing on putative downstream target genes that could be implicated in these processes.

It has been recently reported that p53-dependent transcriptional regulation of Notch 1 expression in keratinocytes inhibits tumor progression (Lefort et al., 2007). Notch is a key regulator of stem cell fate determination and differentiation, but it also ap- 
A

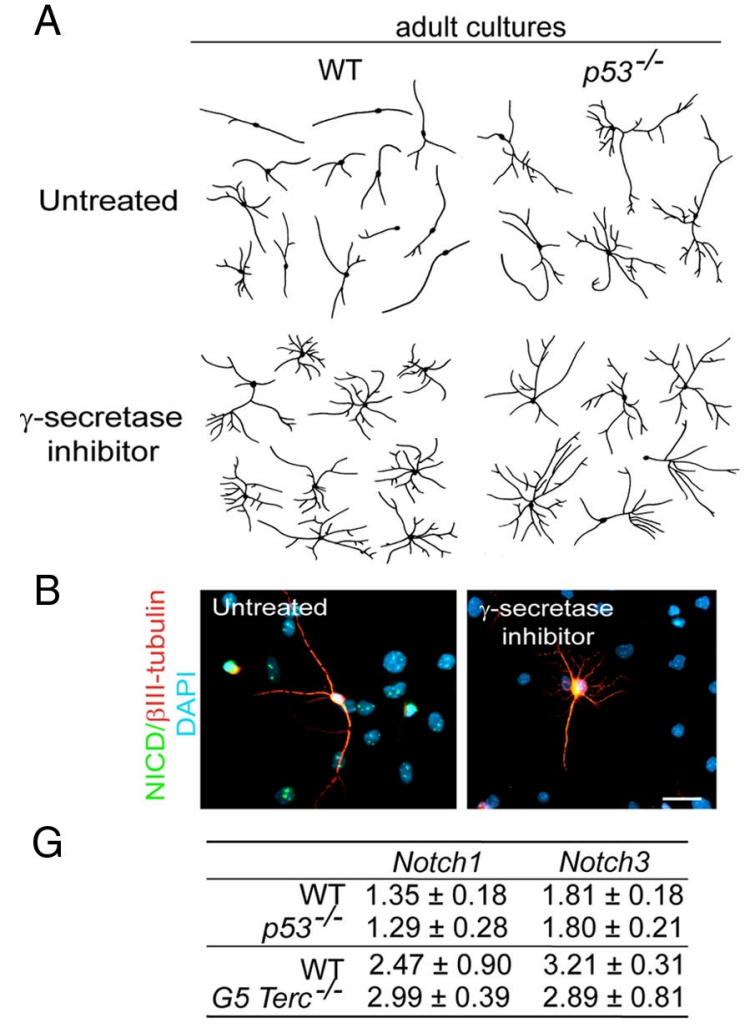

C

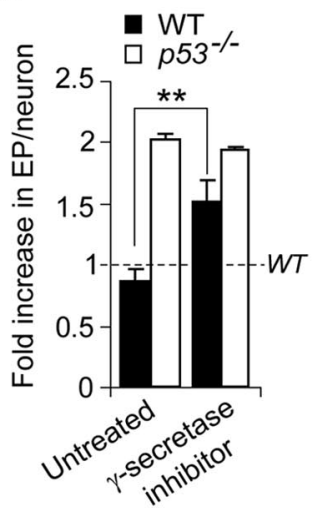

$E$

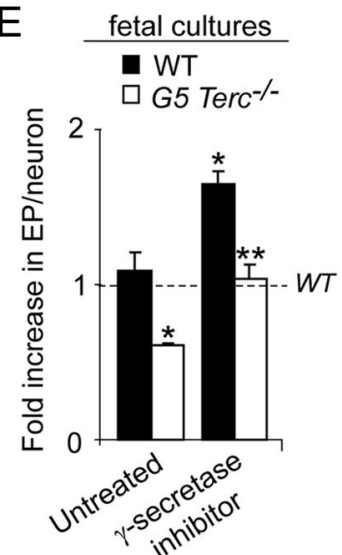

D

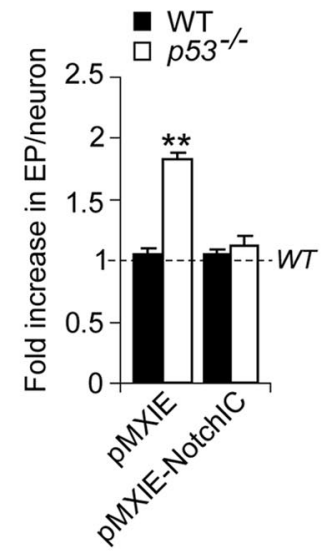

$\mathrm{F}$
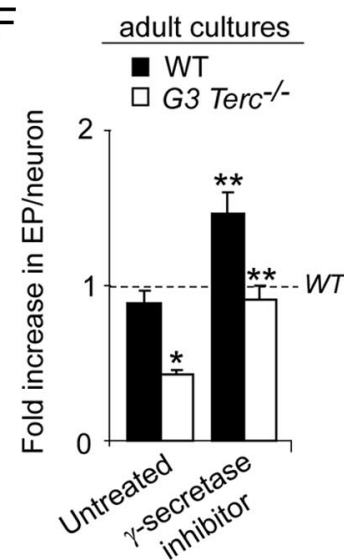

Figure 6. $p 53$ and Notch regulate neuritogenesis. A, Representative drawings of $\beta$ III-tubulin + neurons differentiated from WT and $p 53^{-/-}$adult cells that were treated with the $\gamma$-secretase inhibitor at $1 \mu \mathrm{m}$. B. Fluorescent micrographs from wild-type differentiated cultures showing the immunostaining with antibodies that specifically recognize the cleaved intracellular fragment of Notch (NICD) (green) and tubulin (red) and counterstained with DAPI (blue). Notice that $\gamma$-secretase inhibition abrogates the appearance of the nuclear NICD immunostaining. C, Graph showing quantifications of end points (EP) in WT and in $p 53^{-1-}$ neurons differentiated for 7 div in the presence of $1 \mu \mathrm{M} \mathrm{L-685.458} \mathrm{(} \gamma$-secretase inhibitor). The untreated condition consisted in the addition of $0.1 \%$ DMSO in which the inhibitor was dissolved. EP values are expressed as fold increase relative to measurements in WT neurons in normal differentiation culture medium (indicated by the dashed line). Notice that the Notch pathway normally inhibits neuritogenesis in WT neurons but not in p53-mutant neurons. D, Graph showing quantifications of EP in WT and $p 53^{-1-}$ neurons transduced with pMXIE or pMXIE-NotchIC constructs and differentiated for 7 div afterward, relative to wild-type values (WT) in the absence of any manipulation (dashed line). Constitutive activation

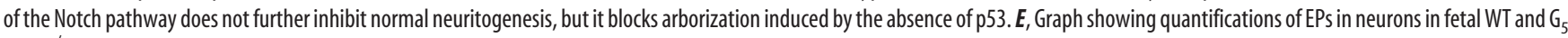
Terc $^{-1-}$ cultures that had been treated with the $\gamma$-secretase inhibitor and differentiated for 7 div. The untreated condition consisted in the addition of $0.1 \%$ DMSO in which the inhibitor was dissolved. EP values are expressed as fold increase relative to measurements in WT neurons in normal differentiation culture medium (indicated by the dashed line). Notice that the treatment causes an increase in the arborization in WT and mutant neurons. $F$, Graph showing quantifications of EPs in neurons in adult WT and $\mathrm{G}_{3}$ Terc $^{-/-}$cultures that had been treated with the $\gamma$-secretase inhibitor and differentiated for 7 div. EP values are expressed as fold increase relative to measurements in WT neurons in normal differentiation culture medium (indicated by the dashed line). Notice that the treatment causes an increase in the arborization in WT and mutant neurons. G, Semiquantitative PCR analysis of Notch 1 and Notch 3 genes in differentiating cultures from WT and p53 ${ }^{-\prime-}$ adult cells and from WT and $\mathrm{G}_{5}$ Terc $^{-1-}$ fetal cells. Notice that no differences were seen in any of the genotypes in the densitometric values relative to the intensity of the $\beta$-actin band used as a control. Error bars indicate SEM. ${ }^{*} p<0.05,{ }^{* *} p<0.01$.

pears to play a role in neuritogenesis in postmitotic neurons, as Notch activity inversely correlates with total neurite length and overall branching (for review, see Whitford et al., 2002; SalamaCohen et al., 2005). Notch 1 and Notch3 are transmembrane receptor proteins that become activated by transmembrane ligands Delta and Jagged. On ligand binding, regulated cleavage of the NICD by a $\gamma$-secretase complex is followed by translocation of the released fragment to the nucleus in which it activates transcription of downstream target genes (Mumm and Kopan, 2000).

To test whether neuritogenesis in our differentiating cultures was dependent on Notch activity, we treated differentiating adult wild-type and $p 53^{-1-}$ cultures with a pharmacological inhibitor of $\gamma$-secretase activity, and analyzed neuritic parameters after 7 div. Inhibition of NICD production and nuclear targeting by treatment of wild-type adult cells with $1 \mu \mathrm{M} \mathrm{L-685.458} \mathrm{during} \mathrm{the}$ differentiation process resulted in more elaborate and lengthier neurites (Fig. $6 A-C$ ), suggesting that endogenous Notch activity does normally prevent neuritic arbors from overexpanding, as previously reported. However, $p 53^{-1-}$ neurites were insensitive to $\gamma$-secretase inhibition (Fig. $6 A-C$ ), a result consistent with the possibility that p53 might modulate neuritogenesis by positively regulating Notch levels.

To explore whether the p53-mutant phenotype was indeed attributable to reduced Notch activity, and therefore insensitive to Notch signaling inhibition, we infected wild-type and $p 53^{-1-}$ adult cells with retroviruses carrying a constitutively active Notchl intracellular fragment (NotchIC) (Hitoshi et al., 2002), a procedure that leads to persistent ligand-independent activation of Notch. NotchIC overexpression leads to enhanced astrogliogenesis along with reduced neurogenesis (supplemental Fig. 5A-C, available at www. jneurosci.org as supplemental material) (Alvarez-Buylla and Lim, 2004; Namihira et al., 2009). When we focused on the neuritic pa- 
A

\begin{tabular}{|c|c|c|c|}
\hline & & Rock1 & Rock2 \\
\hline WT & $\begin{array}{r}\text { pMXIE } \\
\text { pMXIE-NotchIC }\end{array}$ & $\begin{array}{c}7.62 \pm 0.52 \\
13.65 \pm 0.98^{*}\end{array}$ & $\begin{array}{l}2.18 \pm 0.29 \\
3.12 \pm 0.59^{*}\end{array}$ \\
\hline$p 53^{-1}$ & $\begin{array}{r}\text { pMXIE } \\
\text { pMXIE-NotchIC }\end{array}$ & $\begin{array}{l}3.29 \pm 1.26 \# \\
9.43 \pm 1.99 *\end{array}$ & $\begin{array}{l}1.39 \pm 0.61 \# \\
4.21 \pm 1.49 * *\end{array}$ \\
\hline & $\begin{array}{r}\text { WT } \\
\text { G5 } \text { Terc }^{-/-}\end{array}$ & $\begin{array}{l}3.38 \pm 0.04 \\
4.57 \pm 0.09 \#\end{array}$ & $\begin{array}{l}0.51 \pm 0.08 \\
0.76 \pm 0.02 \#\end{array}$ \\
\hline
\end{tabular}

B

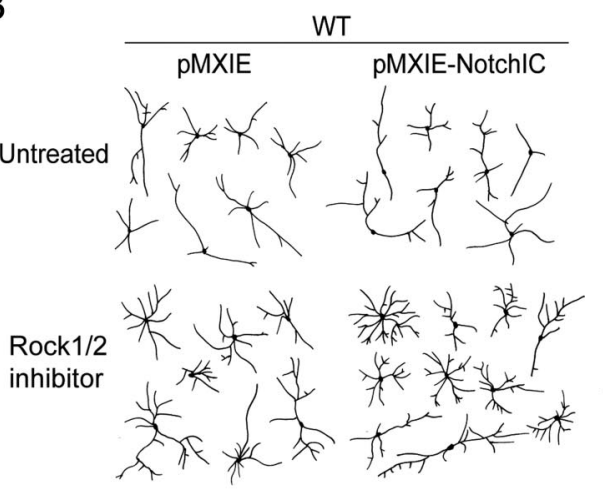

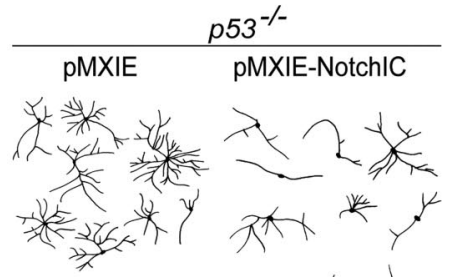

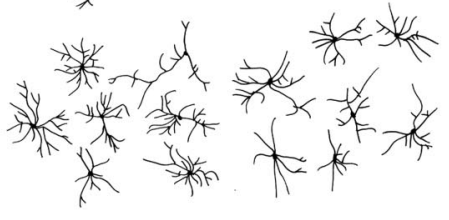

C

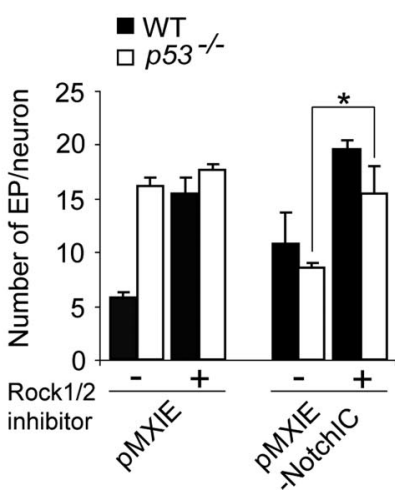

D

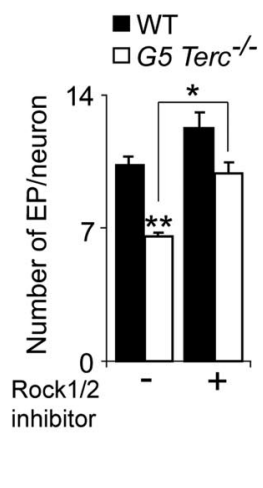

E

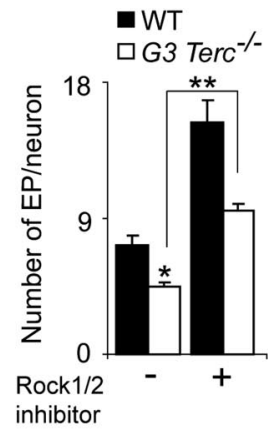

$\mathrm{F}$

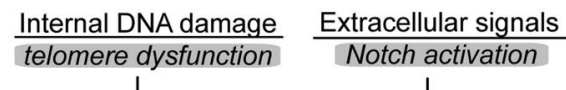

Figure 7. $p 53$ and Notch cooperate to regulate neuritogenesis through Rock1/2. A, Semiquantitative PCR analysis of Rock1 and Rock2 genes in WT and p53 ${ }^{-1-}$ adult differentiated cells transduced with pMXIE or pMXIE-NotchIC, as well as in WT and $\mathrm{G}_{5}$ Terc $^{-1-}$ fetal cultures. Statistical differences between control and NotchIC-transduced cells are indicated with an asterisk $\left(^{*}\right)$ and between genotypes with a pound sign (\#). Lack of $p 53$ results in reduced levels of both Rock 1 and 2 and Notch overexpression upregulates the expression of both genes and compensates for the lack of p53. B, Representative drawings of $\beta$ III-tubulin + neurons differentiated from WT and $p 53^{-1-}$ adult cultures transduced with pMXIE or pMXIE-NotchIC, and treated or not with the Rock1/2 inhibitor H-1152 at $1 \mu \mathrm{M}$. C, Graph showing quantification of EP in WT and in $p 53^{-1-}$ neurons that were transduced with pMXIE or pMXIE-NotchlC and differentiated for 7 div with or without the Rock1/2 inhibitor. D, Graph showing quantification of neuronal end points (EP) in fetal WT and $\mathrm{G}_{5}$ Terc $^{-/-}$cultures differentiated in the presence or in the absence of the Rock $1 / 2$ inhibitor. Notice that the reduction in the number of EP/neuron displayed by the mutant neurons is rescued when Rock1/2 are inhibited. $E$, Graph showing the quantification of neuronal end points (EP) in neurons in adult WT and $\mathrm{G}_{3}$ Terc $^{-1-}$ cultures differentiated in the presence or in the absence of the Rock $1 / 2$ inhibitor. Notice that the reduction in the number of EP/neuron displayed by the mutant neurons is rescued when Rock $1 / 2$ are inhibited. $\boldsymbol{F}$, Proposed model to explain how telomere dysfunction-mediated p53 activation can interact with extracellular Notch to regulate neuritogenesis. Error bars indicate SEM. ${ }^{*} p<0.05,{ }^{* *} p<0.01 ;{ }^{\#} p<0.05$.

rameters of neurons differentiated for 7 div in these cultures, we observed that NotchIC overexpression completely rescued the profuse arborization phenotype exhibited by $p 53^{-1-}$ neurons, although constitutive activation of Notch did not alter the complexity of the neuritic arbors in wild-type cultures (suggesting that Notch blocking effect on neuritogenesis is already maximal) (Fig. 6D). In line with these data, pharmacological suppression of Notch signaling in $\mathrm{G}_{5}$ $\mathrm{Terc}^{-1-}$ embryonic and $\mathrm{G}_{3} \mathrm{Terc}^{-1-}$ adult cultures, which have elevated levels of p53, was sufficient to rescue the stunted phenotype of the mutant neurons (Fig. 6E, F).

All these results were consistent with the possibility that Notch1 was a p53-target gene in our cells. However, we were not able to detect any changes in Notch1 or Notch 3 mRNA levels in adult p53-deficient (absence of p53) or fetal $G_{5}$ Terc-deficient (excess of p53) cells (Fig. 6G). Thus, in contrast to results in keratinocytes, Notch does not appear to be a downstream target of p53 in neural cells, although constitutive activation of Notch signaling rescues the neuritic p53 mutant phenotype. These results suggested that p53 and Notch might be acting in parallel to regulate neuritogenesis.

Neurite sprouting is ultimately dependent on pathways regulating actin dynamics (Luo, 2002) and an inverse relationship has been described between the induction of the small GTPase actin- regulator RhoA or its downstream effectors, the RhoA-associated coiled serine/threonine kinases (Rock1 and Rock2), and neurite extension (Kozma et al., 1997; Hirose et al., 1998). Cooperative positive effects of p53 and Notch in regulating the expression of Rock1 and 2 have been reported in keratinocytes (Lefort et al., 2007). Because our data revealed a putative interplay between Notch signaling and p53, we decided to analyze their interaction in the regulation of these kinases. Both Rock 1 and Rock 2 mRNA levels were under the control of p53 and Notch in our cultures. We observed reduced levels of Rock 1 and 2 in adult cells lacking p53 and increased levels in $G_{5}$ Terc-deficient fetal cultures that have higher levels of $\mathrm{p} 53$. NotchIC overexpression also resulted in increased mRNA levels for both genes, and more importantly, it rescued the reduction observed in $p 53^{-1-}$ cells to wild-type levels (Fig. 7A). These data suggested that p53 and Notch could act in concert to regulate Rock1 and 2 transcriptions in neural cells as they do in keratinocytes.

To functionally assess that changes in Rock $1 / 2$ activity were mediating the effects of $\mathrm{p} 53$ and Notch in the neuronal differentiation of NSCs, we treated wild-type and $p 53^{-/-}$adult cells transduced with either pMXIE-NotchIC-gfp or pMXIE-gfp with the Rock1/2 pharmacological inhibitor $\mathrm{H}-1152$ and analyzed the morphology of the GFP + neurons. In wild-type neurons, inhi- 
bition of Rock1/2 activities resulted in more elaborate arbors, a result consistent with the described role of RhoA kinases in neuritogenesis inhibition (Fig. $7 \mathrm{~B}, \mathrm{C}$ ). Branching in $p 53^{-1-}$ neurons was insensitive to Rock1/2 inhibition, in accordance with our result that lack of p53 reduces Rock1/2 levels. However, the rescuing effect of NotchIC overexpression on the $p 53^{-1-}$ phenotype was completely abrogated in the presence of Rock $1 / 2$ inhibitor $\mathrm{H}-1152$ (Fig. $7 \mathrm{~B}, \mathrm{C}$ ), an indication that Notch activity restores the p53 mutant neuritic phenotype to control values by upregulating the expression of the RhoA kinases. Moreover, H-1152-treated fetal $\mathrm{G}_{5} \operatorname{Terc}^{-1-}$ and adult $\mathrm{G}_{3}$ Terc $^{-1-}$ neurons exhibited more branches than untreated mutant neurons, a result consistent with the observation that increased levels of Rock $1 / 2$ in cells with activated p53 inhibit neuritogenesis (Fig. 7D,E). These results support our proposal that neuritic deficits caused by telomere attrition are, at least in part, mediated by p53-dependent upregulated levels of Rock1/2. Moreover, our results indicate that this pathway acts in parallel with the Notch pathway, suggesting that terminal differentiation in neuronal populations may depend on the combined action of extracellular signaling pathways and sensors of internal damage (Fig. $7 F$ ).

\section{Discussion}

It is becoming increasingly clear that adult stem cells do bear an unlimited capacity to replicate themselves, partly because telomerase activity may not be sufficient to completely preserve telomere lengths in lifelong replicating cells. A relationship between telomere dysfunction in stem cells and aging is supported by the accelerated senescent phenotype of telomerase-deficient mice (Flores et al., 2006). The observations that NSC telomeres shorten with age and that neurogenesis is impaired in telomerasedeficient mice suggest that telomere dynamics may also play a role in neurogenic niches during aging. Our results support a model whereby accumulated telomere shortening do impact on the potential of NSC populations to persist but also on the capacity of their progeny to terminal differentiate into fully mature neurons, suggesting that age-associated physiological impairments in neural structures that are supported by brainstem cells may additionally be attributable to abnormal differentiation. Our results also indicate that p53 is a central regulator of a novel checkpoint that limits the ability of different somatic stem cells with dysfunctional telomeres to regenerate adult tissues. In addition, the observation that the proliferative advantage displayed by p53-deficient cells (Gil-Perotin et al., 2006; Meletis et al., 2006; our present data) can be counteracted by telomere shortening supports the notion that absence of telomere maintenance in postnatal individuals may act as a tumor-suppressive mechanism (Serrano and Blasco, 2007).

Although the potential roles of telomere dynamics in adult stem cells are beginning to be elucidated (Flores et al., 2006), studies on the potential effects of telomere dysfunction on their differentiation are very scarce. There is an increasing recognition, however, of the potential relationship between DNA damage/ telomere erosion and stem cell differentiation. Hematopoietic stem cell aging correlates with accumulated genomic damage and results in a skewing of lineage potential from lymphopoiesis toward myelopoiesis (Rossi et al., 2008), and epidermal stem cell mobilization toward keratinocyte differentiation or osteogenic potential in mesenchymal cells are severely impaired in lategeneration Terc mutants (Liu et al., 2004; Flores et al., 2005). However, because cells with dysfunctional telomeres usually exhibit abnormal cell cycling, these defects could be a consequence of a deficient proliferative history. Our results in fetal NSCs dem- onstrate for the first time that telomere attrition can cause impairments in terminal differentiation in a manner that is independent from its effects on cell cycling.

We have shown that all adverse effects of telomere dysfunction on brainstem cells, including those on neuronal differentiation and neuritogenesis, are mediated by activation of p53. Potentiating effects of p53 ablation on adult neurogenesis have been previously reported (Gil-Perotín et al., 2006; Meletis et al., 2006). Conversely, reduction in NSC proliferation in the adult SEZ associated to an accelerated decline with age in the number of SEZ proliferating cells and in olfactory discrimination has been observed in mice overexpressing a constitutively active truncated form of p53 (p44Tg mice) (Medrano et al., 2007). Previous studies have demonstrated that many senescent phenotypes in telomerase-deficient mice are indeed mediated by effects of activated p53 on the transcription of genes involved in cell cycle arrest and/or apoptosis (Chin et al., 1999; d'Adda di Fagagna et al., 2003; Flores and Blasco, 2009). Our data point to an additional direct role of p53 in cell differentiation. All these results suggest that p53 is a central player of a novel checkpoint that limits the ability of different somatic stem cells with dysfunctional telomeres to regenerate adult tissues, including the brain.

The potential implication of p53 in the differentiation of neuronal precursors and of hippocampal and cerebellar neurons has been reported previously (Eizenberg et al., 1996; Ferreira and Kosik, 1996; Komarova et al., 1997; Armesilla-Diaz et al., 2009). Neuronal differentiation has not been analyzed in p44Tg mice; however, results in vivo obtained in mice that overexpress wildtype p53 demonstrate the ability of p53 to affect cellular differentiation in other systems. Transgenic mice overexpressing p53 in a tissue-restricted manner exhibit abnormal differentiation resulting in atrophy of the organ targeted by the transgene expression (i.e., altered lens differentiation leading to microphthalmia or kidney atrophy with no changes in apoptosis or cell cycling) (Nakamura et al., 1995; Godley et al., 1996). It is unclear what the mechanism(s) for the negative effect of shortened telomeres and p53 on cell differentiation in these different systems are. We have shown that specific defects of telomere shortening and p53 activation on neuritogenesis can be antagonized by Notch activity or by inhibition of RhoA effectors Rock $1 / 2$ and that expression of these latter molecules appears to be under the control of p53 activation, providing a link between DNA damage and deficient neuritogenesis. In contrast to results in primary human keratinocytes (Lefort et al., 2007), we did not obtain any evidence that p53 modulates Notch expression in NSCs. Because overexpression of a constitutively active Notch completely rescues the p53 mutant phenotype, we cannot exclude the possibility that $\mathrm{p} 53$ regulates other molecules in the Notch pathway (Mumm and Kopan, 2000). Our data indicate, however, that expression of Rock1 and 2 are modulated by activation of p53 and Notch. It has been previously shown that expression of the Rock 2 gene in keratinocytes is under the negative control of Hes1, a classical Notch-dependent transcriptional repressor, and of p53 acting in parallel (Lefort et al., 2007). Our data indicate that both p53 and Notch positively regulate Rock 1 and 2, and rescue experiments suggest that they do so in concert. Additional work will be necessary to determine possible direct effects of p53 and Notch-dependent transcription factors on the promoters of these genes. Alternatively, potential nongenomic interactions of p53 and Notch signaling with Rock/RhoA remain also possible. No matter what the precise mechanism(s) may be, our data indicate that neuritogenesis in differentiating neurons is sensitive to both extracellular signaling pathways, such 
as Notch, and internal DNA damage sensors, such as p53, in a coordinated way.

We cannot exclude the possibility that other mechanisms might be involved in p53 effects on neuritogenesis. We have shown that expression of $\mathrm{p} 21$, but not expression of downstream proapoptotic molecules, is upregulated in NSCs with short telomeres and active $\mathrm{p} 53$. Increasing evidence suggests that $\mathrm{p} 21$ plays roles in differentiation of neural progenitor cells and of keratinocytes, in a cell cycle-independent way (Tanaka et al., 2002; Devgan et al., 2006). Additional studies will be necessary to determine $\mathrm{p} 21$ contribution in NSC response to telomere shortening, although it may also differ from that of p53. Both p 21 and p53-deficient adult NSCs exhibit increased proliferation, but, whereas p53-deficient NSCs are more clonogenic, NSCs that lack a functional p21 exhibit defects in self-renewal (Kippin et al., 2005; Gil-Perotin et al., 2006; Meletis et al., 2006). Interestingly, although telomerase mutants that also lack p53 do not survive longer than those with an intact p53 checkpoint, a p21 deficiency extends the life span of mice bearing dysfunctional telomeres without accelerating cancer formation (Choudhury et al., 2007). Recently, inhibition of the shelterin protein TRF2, which participates in the capping of uncompromised telomeres, has been shown to modulate neuronal differentiation by telomere-independent actions on gene silencing. Lack of TRF2 leads to REST degradation and subsequent de-repression of REST-targeted neural genes, resulting in acquisition of neuronal phenotypes (Zhang et al., 2008). However, we could not see any changes in REST protein levels in p53-deficient neurosphere cultures relative to wild-type cultures (S. R. Ferrón and I. Fariñas, unpublished results). Interestingly, selective damage to telomeres without affecting TRF2 levels does not cause REST degradation (Zhang et al., 2008). The same report indicated that telomere damage did not cause alterations in cell differentiation, suggesting that there could be differences between cell lines (immortalized, usually bearing high telomerase levels) and primary progenitors like the ones used in the present work.

The possibility that stem cells could be used as a therapeutic approach to age-related brain disorders has fueled studies about the effects of aging in the functionality of stem cells. Furthermore, the prospect that stem cells from endogenous reservoirs could be recruited for aged brain repair highlights the relevance of studying the impact of genomic instability and age-related intrinsic limits in NSC potentialities. Changes in niche extracellular growth factors and in circulating molecules appear to reduce proliferation of adult somatic stem cells. Indeed, examination of components of the EGF and FGF signaling pathways has suggested that a decreased response to mitogenic stimulation could underlie the progressive decay in SEZ neurogenic activity (Jin et al., 2003; Enwere et al., 2004; Maslov et al., 2004). However, alternative mechanisms such as increased levels of intracellular cell cycle inhibitory molecules or accumulated genomic damage, including telomere shortening, could certainly play a role in the aging of neurogenic populations, among other adult stem cell populations (Molofsky et al., 2006; Rossi et al., 2008). It has been proposed that recruitment strategies could be viable in the treatment of neurodegeneration because aged neurogenic areas of the brain can respond to growth factors with increased proliferation (Jin et al., 2003). However, successful integration of stem cell progeny requires their full differentiation, which may be limited cell autonomously, as suggested by our data.

\section{References}

Ahlenius H, Visan V, Kokaia M, Lindvall O, Kokaia Z (2009) Neural stem and progenitor cells retain their potential for proliferation and differen- tiation into functional neurons despite lower number in aged brain. J Neurosci 29:4408-4419.

Alvarez-Buylla A, Lim DA (2004) For the long run: maintaining germinal niches in the adult brain. Neuron 41:683-686.

Armesilla-Diaz A, Bragado P, Del Valle I, Cuevas E, Lazaro I, Martin C, Cigudosa JC, Silva A (2009) p53 regulates the self-renewal and differentiation of neural precursors. Neuroscience 158:1378-1389.

Blasco MA (2002) Telomerase beyond telomeres. Nat Rev Cancer 2:627-633.

Blasco MA, Lee HW, Hande MP, Samper E, Lansdorp PM, DePinho RA, Greider CW (1997) Telomere shortening and tumor formation by mouse cells lacking telomerase RNA. Cell 91:25-34.

Brynczka C, Labhart P, Merrick BA (2007) NGF-mediated transcriptional targets of $\mathrm{p} 53$ in PC12 neuronal differentiation. BMC Genomics 8:139.

Caporaso GL, Lim DA, Alvarez-Buylla A, Chao MV (2003) Telomerase activity in the subventricular zone of adult mice. Mol Cell Neurosci 23:693-702.

Cheng A, Shin-ya K, Wan R, Tang SC, Miura T, Tang H, Khatri R, Gleichman M, Ouyang X, Liu D, Park HR, Chiang JY, Mattson MP (2007) Telomere protection mechanisms change during neurogenesis and neuronal maturation: newly generated neurons are hypersensitive to telomere and DNA damage. J Neurosci 27:3722-3733.

Chin L, Artandi SE, Shen Q, Tam A, Lee SL, Gottlieb GJ, Greider CW, DePinho RA (1999) p53 deficiency rescues the adverse effects of telomere loss and cooperates with telomere dysfunction to accelerate carcinogenesis. Cell 97:527-538.

Choudhury AR, Ju Z, Djojosubroto MW, Schienke A, Lechel A, Schaetzlein S, Jiang H, Stepczynska A, Wang C, Buer J, Lee HW, von Zglinicki T, Ganser A, Schirmacher P, Nakauchi H, Rudolph KL (2007) Cdknla deletion improves stem cell function and lifespan of mice with dysfunctional telomeres without accelerating cancer formation. Nat Genet 39:99-105.

Contente A, Dittmer A, Koch MC, Roth J, Dobbelstein M (2002) A polymorphic microsatellite that mediates induction of PIG3 by p53. Nat Genet 30:315-320.

d'Adda di Fagagna F, Reaper PM, Clay-Farrace L, Fiegler H, Carr P, Von Zglinicki T, Saretzki G, Carter NP, Jackson SP (2003) A DNA damage checkpoint response in telomere-initiated senescence. Nature 426: 194-198.

Devgan V, Mammucari C, Millar SE, Brisken C, Dotto GP (2005) p21WAF1/ Cip1 is a negative transcriptional regulator of Wnt4 expression downstream of Notch1 activation. Genes Dev 19:1485-1495.

Eizenberg O, Faber-Elman A, Gottlieb E, Oren M, Rotter V, Schwartz M (1996) p53 plays a regulatory role in differentiation and apoptosis of central nervous system-associated cells. Mol Cell Biol 16:5178-5185.

Enwere E, Shingo T, Gregg C, Fujikawa H, Ohta S, Weiss S (2004) Aging results in reduced epidermal growth factor receptor signaling, diminished olfactory neurogenesis, and deficits in fine olfactory discrimination. J Neurosci 24:8354-8365.

Ferreira A, Kosik KS (1996) Accelerated neuronal differentiation induced by p53 suppression. J Cell Sci 109:1509-1516.

Ferrón S, Mira H, Franco S, Cano-Jaimez M, Bellmunt E, Ramírez C, Fariñas I, Blasco MA (2004) Telomere shortening and chromosomal instability abrogates proliferation of adult but not embryonic neural stem cells. Development 131:4059-4070.

Ferrón SR, Andreu-Agulló C, Mira H, Sanchez P, Marqués-Torrejón MA, Fariñas I (2007) A combined ex/in vivo assay to detect effects of exogenously added factors in neural stem cells. Nat Protoc 2:849-859.

Flores I, Blasco MA (2009) A p53-dependent response limits epidermal stem cell functionality and organismal size in mice with short telomeres. PLoS One 4:e4934.

Flores I, Cayuela ML, Blasco MA (2005) Effects of telomerase and telomere length on epidermal stem cell behavior. Science 309:1253-1256.

Flores I, Benetti R, Blasco MA (2006) Telomerase regulation and stem cell behaviour. Curr Opin Cell Biol 18:254-260.

Flores I, Canela A, Vera E, Tejera A, Cotsarelis G, Blasco MA (2008) The longest telomeres: a general signature of adult stem cell compartments. Genes Dev 22:654-667.

Gil-Perotin S, Marin-Husstege M, Li J, Soriano-Navarro M, Zindy F, Roussel MF, Garcia-Verdugo JM, Casaccia-Bonnefil P (2006) Loss of p53 induces changes in the behavior of subventricular zone cells: implication for the genesis of glial tumors. J Neurosci 26:1107-1116.

Godley LA, Kopp JB, Eckhaus M, Paglino JJ, Owens J, Varmus HE (1996) 
Wild-type p53 transgenic mice exhibit altered differentiation of the ureteric bud and possess small kidneys. Genes Dev 10:836-850.

Herbig U, Ferreira M, Condel L, Carey D, Sedivy JM (2006) Cellular senescence in aging primates. Science 311:1257-1260.

Herrera E, Samper E, Martín-Caballero J, Flores JM, Lee HW, Blasco MA (1999) Disease states associated to telomerase deficiency appear earlier in mice with short telomeres. EMBO J 18:2950-2960.

Hirose M, Ishizaki T, Watanabe N, Uehata M, Kranenburg O, Moolenaar WH, Matsumura F, Maekawa M, Bito H, Narumiya S (1998) Molecular dissection of the Rho-associated protein kinase (p160ROCK)-regulated neurite remodeling in neuroblastoma N1E-115 cells. J Cell Biol 141:1625-1636.

Hitoshi S, Alexson T, Tropepe V, Donoviel D, Elia AJ, Nye JS, Conlon RA, Mak TW, Bernstein A, van der Kooy D (2002) Notch pathway molecules are essential for the maintenance, but not the generation, of mammalian neural stem cells. Genes Dev 16:846-858.

Jin K, Sun Y, Xie L, Batteur S, Mao XO, Smelick C, Logvinova A, Greenberg DA (2003) Neurogenesis and aging: FGF-2 and HB-EGF restore neurogenesis in hippocampus and subventricular zone of aged mice. Aging Cell 2:175-183.

Kippin TE, Martens DJ, van der Kooy D (2005) p21 loss compromises the relative quiescence of forebrain stem cell proliferation leading to exhaustion of their proliferation capacity. Genes Dev 19:756-767.

Komarova EA, Chernov MV, Franks R, Wang K, Armin G, Zelnick CR, Chin DM, Bacus SS, Stark GR, Gudkov AV (1997) Transgenic mice with p53responsive lacZ: p53 activity varies dramatically during normal development and determines radiation and drug sensitivity in vivo. EMBO J 161391-161400.

Kozma R, Sarner S, Ahmed S, Lim L (1997) Rho family GTPases and neuronal growth cone remodelling: relationship between increased complexity induced by $\mathrm{Cdc} 42 \mathrm{Hs}$, Racl, and acetylcholine and collapse induced by RhoA and lysophosphatidic acid. Mol Cell Biol 17:1201-1211.

Kruk PA, Balajee AS, Rao KS, Bohr VA (1996) Telomere reduction and telomerase inactivation during neuronal cell differentiation. Biochem Biophys Res Commun 224:487-492.

Lefort K, Mandinova A, Ostano P, Kolev V, Calpini V, Kolfschoten I, Devgan V, Lieb J, Raffoul W, Hohl D, Neel V, Garlick J, Chiorino G, Dotto GP (2007) Notch1 is a p53 target gene involved in human keratinocyte tumor suppression through negative regulation of ROCK1/2 and MRCKalpha kinases. Genes Dev 21:562-577.

Liu L, DiGirolamo CM, Navarro PA, Blasco MA, Keefe DL (2004) Telomerase deficiency impairs differentiation of mesenchymal stem cells. Exp Cell Res 294:1-8.

Lledó PM, Alonso M, Grubb MS (2006) Adult neurogenesis and functional plasticity in neuronal circuits. Nat Rev Neurosci 7:179-193.

Luo L (2002) Actin cytoskeleton regulation in neuronal morphogenesis and structural plasticity. Annu Rev Cell Dev Biol 18:601-635.

Luo J, Daniels SB, Lennington JB, Notti RQ, Conover JC (2006) The aging neurogenic subventricular zone. Aging Cell 5:139-152.

Maslov AY, Barone TA, Plunkett RJ, Pruitt SC (2004) Neural stem cell detection, characterization and age-related changes in the subventricular zone of mice. J Neurosci 24:1726-1733.

Medrano S, Burns-Cusato M, Atienza MB, Rahimi D, Scrable H (2007) Regenerative capacity of neural precursors in the adult mammalian brain is under the control of p53. Neurobiol Aging 30:483-497.

Meletis K, Wirta V, Hede SM, Nistér M, Lundeberg J, Frisén J (2006) p53 suppresses the self-renewal of adult neural stem cells. Development 133:363-369.

Molofsky AV, Slutsky SG, Joseph NM, He S, Pardal R, Krishnamurthy J, Sharpless NE, Morrison SJ (2006) Increasing p16INK4a expression decreases forebrain progenitors and neurogenesis during ageing. Nature 443:448-452.
Mumm JS, Kopan R (2000) Notch signaling: from the outside in. Dev Biol 228:151-165.

Nakamura T, Pichel JG, Williams-Simons L, Westphal H (1995) An apoptotic defect in lens differentiation caused by human p53 is rescued by a mutant allele. Proc Natl Acad Sci U S A 92:6142-6146.

Namihira M, Kohyama J, Semi K, Sanosaka T, Deneen B, Taga T, Nakashima K (2009) Committed neuronal precursors confer astrocytic potential on residual neural precursor cells. Dev Cell 16:245-255.

Prowse KR, Greider CW (1995) Developmental and tissue-specific regulation of mouse telomerase and telomere length. Proc Natl Acad Sci U S A 23:4818-4822.

Rando TA (2006) Stem cells, ageing, and the quest for immortality. Nature 441:1080-1086.

Rao MS, Hattiangady B, Abdel-Rahman A, Stanley DP, Shetty AK (2005) Newly born cells in the ageing dentate gyrus display normal migration, survival and neuronal fate choice but endure retarded early maturation. Eur J Neurosci 21:464-476.

Reynolds BA, Weiss S (1992) Generation of neurons and astrocytes from isolated cells of the adult mammalian central nervous system. Science 255:1707-1710.

Richardson RM, Nguyen B, Holt SE, Broaddus WC, Fillmore HL (2007) Ectopic telomerase expression inhibits neuronal differentiation of NT2 neural progenitor cells. Neurosci Lett 421:168-172.

Rossi DJ, Jamieson CH, Weissman IL (2008) Stems cells and the pathways to aging and cancer. Cell 132:681-696.

Rudolph KL, Chang S, Lee HW, Blasco M, Gottlieb GJ, Greider C, DePinho RA (1999) Longevity, stress response, and cancer in aging telomerasedeficient mice. Cell 96:701-712.

Salama-Cohen P, Arévalo MA, Meier J, Grantyn R, Rodríguez-Tébar A (2005) NGF controls dendrite development in hippocampal neurons by binding to p75NTR and modulating the cellular targets of Notch. Mol Biol Cell 16:339-347.

Serrano M, Blasco MA (2007) Cancer and ageing: convergent and divergent mechanisms. Nat Rev Mol Cell Biol 8:715-722.

Shi S, Gronthos S, Chen S, Reddi A, Counter CM, Robey PG, Wang CY (2002) Bone formation by human postnatal bone marrow stromal stem cells is enhanced by telomerase expression. Nat Biotechnol 20:587-591.

Simonsen JL, Rosada C, Serakinci N, Justasen J, Stenderup K, Rattan SI, Jensen TG, Kassem M (2002) Telomerase expression extends the proliferative life-span and maintains the osteogenic potential of human bone marrow stromal cells. Nat Biotechnol 20:560-561.

Tanaka H, Yamashita T, Asada M, Mizutani S, Yoshikawa H, Tohyama M (2002) Cytoplasmic p21 (Cip1/WAF1) regulates neurite remodeling by inhibiting Rho-kinase activity. J Cell Biol 158:321-329.

Tropepe V, Craig CG, Morshead CM, van der Kooy D (1997) Transforming growth factor-alpha null and senescent mice show decreased neural progenitor cell proliferation in the forebrain subependyma. J Neurosci 17:7850-7859.

Vogelstein B, Lane D, Levine AJ (2000) Surfing the p53 network. Nature 408:307-310.

Whitford KL, Dijkhuizen P, Polleux F, Ghosh A (2002) Molecular control of cortical dendrite development. Annu Rev Neurosci 25:127-149.

Whitman MC, Greer CA (2007) Adult-generated neurons exhibit diverse developmental fates. Dev Neurobiol 67:1079-1093.

Zhang P, Pazin MJ, Schwartz CM, Becker KG, Wersto RP, Dilley CM, Mattson MP (2008) Nontelomeric TRF2-REST interaction modulates neuronal gene silencing and fate of tumor and stem cells. Curr Biol 18:1489-1494.

Zhao C, Deng W, Gage FH (2008) Mechanisms and functional implications of adult neurogenesis. Cell 132:645-660. 